2nd Department of Medicine and Cardiology Center, Medical Faculty, Albert Szent-Györgyi Clinical Center, University of Szeged

Novel opportunities for the evaluation of vascular function in the cardiac catheterization laboratory

\author{
Viktor Sasi MD
}

PhD thesis

Tutor:

Prof. Attila Nemes MD, PhD, DSc 


\section{Relevant publications}

\section{Full papers}

I. Nagy FT, Nemes A, Szücsborus T, Ungi T, Katona A, Sasi V, Zimmermann Z, Kalapos A, Forster T, Ungi I. Validation of videodensitometric myocardial perfusion assessment. Cent Eur J Med 2013; 8: 600-607 (Impact Factor: 0.209)

II. Sasi V, Kalapos A, Gavallér H, Domsik P, Ungi T, Zimmermann Z, Nagy FT, Horváth T, Forster T, Nemes A. Relationship between early myocardial reperfusion assessedby videodensitometry and late left ventricular function Results following invasive treatment of acute myocardial infarction. Orv Hetil 2014; 155: 187-193.

III. Sasi V, Gavallér H, Kalapos A, Domsik P, Nagy FT, Ungi T, Ungi I, Forster T, Nemes A. Prediction of myocardial tissue loss by quantitative densitometric myocardial blush parameters following ST-elevation myocardial infarction. Acta Physiol Hung 2015; 102: 206-215. (Impact Factor: 0.734)

IV. Nemes A, Kalapos A, Sasi V, Ungi T, Ungi I, Forster T, Sepp R. Videodensitometric time-density curve change after alcohol 5 septal ablation of obstructive hypertrophic cardiomyopathy. Neth Heart J 2015; 23: 143-144. (Impact factor: 1.837)

V. Sasi V, Ungi I, Forster T, Nemes A. Multiple coronary fistulas originating from all major coronary arteries. Acta Cardiol 2010; 65: 357-360. (Impact factor: 0.65)

VI. Sasi V, Nemes A, Forster T, Ungi I. Functional assessment of a left coronarypulmonary artery fistula by coronary flow reserve. Postep Kardiol Inter 2014; 10, 2: 141-143. (Impact factor: 0.066)

\section{Abstracts}

I. Sasi V, Ungi I, Thury A, Sepp R, Nagy F, Hausinger P, Szücsborus T, Forster T, Nemes A. Assessment of functional sigificance of coronary fistulas. Cardiol Hung 2012; 42: A112-113. 
II. Nagy FT, Nemes A, Szücsborus T, Sasi V, Kalapos A, Zimmermann Z, Katona A, Forster T, Ungi I. Validation of videodensitometric perfusion assessment by index of myocardial resistance and coronary flow reserve. Cardiol Hung 2013; 43: B25.

III. Sasi V, Kalapos A, Domsik P, Nagy FT, Horváth T, Hausinger P, Forster T, Ungi I, Nemes A. Final quantitative regional myocardial blush correlates with clinical parameters and extent and transmurality of infarction derived by cardiac MR in patients suffering ST elevation myocardial infarction. Cardiol Hung 2013; 43: B81. 


\section{Table of contents}

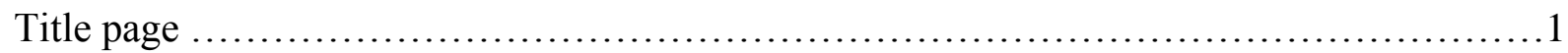

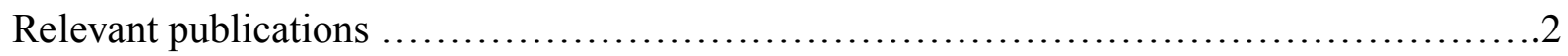

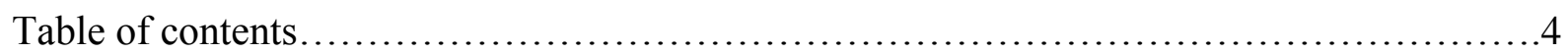

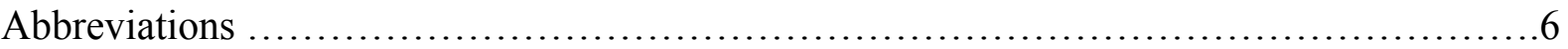

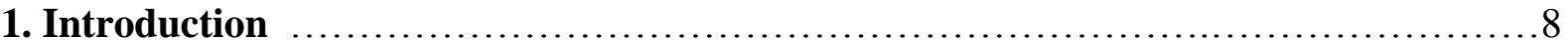

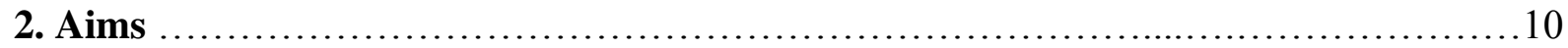

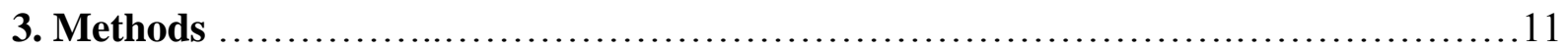

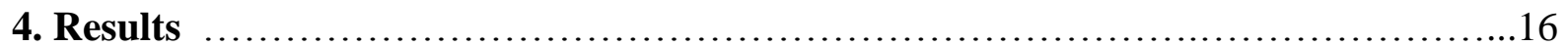

4.1. Videodensitometric myocardial perfusion assessment............................16

4.1.1. Validation of videodenzitometric myocardial perfusion assessment.................16

4.1.2. Relationship between early myocardial reperfusion assessedby videodensitometry and late left ventricular function Results following invasive treatment of acute myocardial infarction.

4.1.3. Prediction of myocardial lost tissue by quantitative densitometric myocardial blush parameters following ST-elevation myocardial infarction.

4.1.4. Videodensitometric time-density curve change after alcohol septal ablation of obstructive

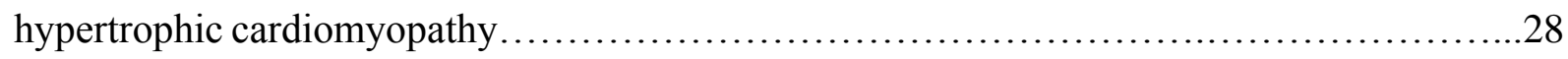

4.2. Functional estimation of coronary fistulas..................................... 30

4.2.1. Multiple coronary fistulas originating from all major coronary arteries...............30

4.2.2. Functional assessment of a left coronary-pulmonary artery fistulas by coronary flow

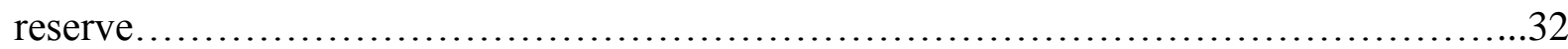

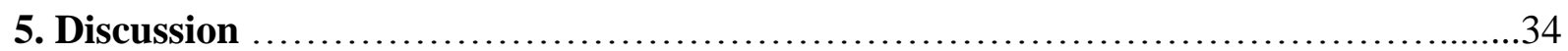

5.1. Videodensitometric myocardial perfusion assessment..............................34

5.1.1. Validation of videodenzitometric myocardial perfusion assessment..................34

5.1.2. Relationship between early myocardial reperfusion assessedby videodensitometry and late left ventricular function Results following invasive treatment of acute myocardial infarction.

5.1.3. Prediction of myocardial lost tissue by quantitative densitometric myocardial blush parameters following ST-elevation myocardial infarction. .38

5.1.4. Videodensitometric time-density curve change after alcohol septal ablation of obstructive

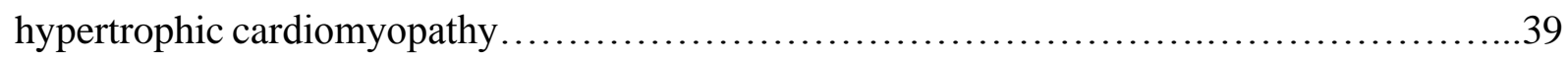

5.2. Functional estimation of coronary fistulas....................................... 39 
5.2.1. Multiple coronary fistulas originating from all major coronary arteries................39

5.2.2. Functional assessment of a left coronary-pulmonary artery fistulas by coronary flow

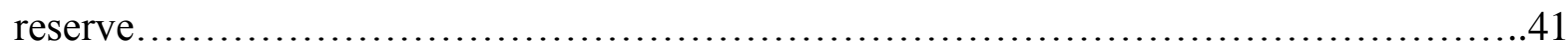

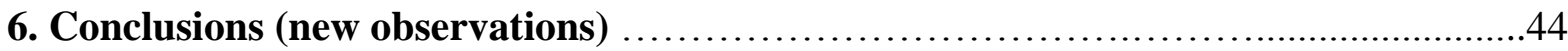

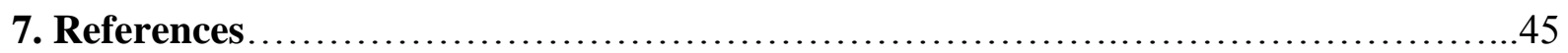

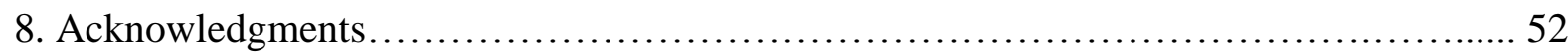




\section{Abbreviations}

BMS - bare metal stent

CFR - coronary flow reserve

$\mathrm{CI}$ - confidence interval

CT - computer tomography

CX - left circumflex coronary artery

DG - diagonal artery

DSA - digital subtraction angiography

$\mathrm{EF}$ - ejection fraction (LV)

ESV - endsystolic volume (LV)

FFR - fractional flow reserve

$\mathrm{G}_{\max }$ - maximal density of the TDC

HOCM - hypertrophic obstructive cardiomyopathy

IMR - index of microcirculatory resistance

LAD - left anterior descending coronary artery

LM - left main coronary artery

LV - left ventricular

MBG - myocardial blush grade

MLI - myocardial loss index

MRI - magnetic resonance imaging

MVD - multivessel disease

$\mathrm{P}_{\mathrm{a}}$ - mean aortic pressure (by guiding catheter)

$\mathrm{P}_{\mathrm{d}}$ - mean distal coronary pressure (by pressure wire)

PA - pulmonary artery

PCI - percutaneous coronary intervention

PET - positron emission tomography

$\mathrm{RC}$ - right coronary artery

ROC - receiver operator characteristic

ROI - region of interest

SPECT - single photon emission computer tomography

STEMI - ST-elevation myocardial infarction

TDC - time-density curve 
$\mathrm{T}_{\max }$ - time-to-reach maximal density of the TDC

TMPG - TIMI myocardial perfusion grade 


\section{Introduction}

Traditionally, the diagnosis and treatment of myocardial ischemia has focused on flow-limiting stenosis of the epicardial arteries. However, in the past two decades it has also become evident that coronary microvascular dysfunction also plays a significant role in a number of disease states. Although in some instances merely epiphenomena, in others it has proven to be a powerful indicator of adverse outcome, and a potential therapeutic target (1). Owing to the growing awareness of the importance of coronary microvascular dysfunction, a number of noninvasive and invasive techniques have been developed to provide functional assessment of the coronary microcirculation (2).

The time-honored invasive method for measurement of microvascular function in the catheterization laboratory is coronary flow reserve (CFR), representing the magnitude of the increase of coronary flow that can be achieved at maximum hyperemia (3). Index of microcirculatory resistance (IMR) is a novel invasive method for the assessment of the status of coronary microcirculation is independent of epicardial artery stenosis $(4,5)$. It is derived from the distal mean coronary pressure and hyperemic mean transit time, and shows superior reproducibility and less haemodynamic dependence then CFR (6). Fractional flow reserve (FFR) is a technique used in coronary catheterization to measure pressure differences across a coronary artery stenosis characterizing its functional significance. FFR is based on simultaneous measurement of mean aortic pressure and mean distal coronary pressure when maximum hyperemia is achieved (7). The above techniques, however have proven to be instrumentation and expense consuming for everyday use in the catheterization laboratory.

There are several methodologies with which myocardial perfusion could be assessed including different isotop techniques (single-photon emission tomography, SPECT) (8), computer tomography (CT) (9), magnetic resonance imaging (MRI) [10], positron emission tomography (PET) (11), and contrast echocardiography (12). Assessment of myocardial perfusion on coronary angiograms is routinely performed by visual estimation. In clinical circumstances, two visual grading scales proved to be informative in assessing perfusion of the infarction-related myocardium: the Myocardial Blush Grade (MBG) (13) and TIMI Myocardial Perfusion Grade (TMPG) (14). Both grades have four levels: grades 0 and 1 representing no or minimal contrast signal in the infarction-related myocardium, while grades 2 and 3 representing impaired and normal states. The inter- and intraobserver variabilities associated with subjective angiographic perfusion assessments are known limitations of these visual grading tools. Korosoglou et al. found that computerized videodensitometric method for the evaluation of 
quantitative MBG is highly predictive for functional recovery in patients after ST elevation myocardial infarction (STEMI)(15).

Our group presented a new method for computerized densitometric analysis on digital subtraction coronary angiograms (DSA) $(16,17)$. This technology seems to be a promising simple tool to assess vascular function in paralell with morphology, but its validity and diagnostic value of densitometry-derived parameters are not well confirmed.

Moreover, there is special problem when fistulous communications exist between coronary arteries and other vessels or heart chambers. In order to assess the functional importance of these fistulous communications, theoretically all the above mentioned methodologies could be used. However, due to rarity of patients with these complications, the experience with their usefulness is limited. 


\section{Aims}

To evaluate the correlations between videodensitometry-derived myocardium perfusion parameters and thermodilution-derived CFR and IMR in patients with stable angina pectoris.

To examine the relationship between myocardial reperfusion as assessed by videodensitometry on coronary angiograms following invasive treatment of STEMI and MRI-derived late left ventricular (LV) function.

To examine the relationship between videodenzitometric myocardial perfusion parameters as assessed on coronary angiograms directly following successful recanalization therapy and MRI-derived myocardial tissue loss late after STEMI.

To demonstrate the usefulness of videodenzitometric myocardial perfusion parameters on the evaluation of success of alcohol septal ablation in obstructive hypertrophic cardiomyopathy (HOCM)

To demonstrate the clinical usefulness of CFR and FFR measurements in the functional evaluation of multiple fistulas originating from all major coronary arteries

To demonstrate the functional evaluation of left coronary-pulmonary artery fistulas by CFR assessment 


\section{Methods}

Patient population (general considerations). Several patient populations were selected to evaluate videodensitometry-derived myocardial perfusion parameters as detailed below at each study at the Division of Invasive Cardiology, Department of Cardiology, University of Szeged, Hungary. Some cases with special fistulous communications are also presented. Informed consent was obtained from each patient and the study protocol conformed to the ethical guidelines of the 1975 Declaration of Helsinki, as reflected in a prior approval by the Institution's Human Research Committee.

Measurement of CFR, IMR and FFR. CFR (18), IMR (4), and FFR (18) were measured according to methods described previously. Briefly, after conventional diagnostic coronary angiography a $6 \mathrm{~F}$ coronary guiding catheter was used to engage the coronary artery. Heparin (5000 IU) and intracoronary Nitroglycerin $(200 \mu \mathrm{g})$ were administered. After equalization an intracoronary pressure and temperature sensor-tipped guide wire (Certus-pressure wire, Radi Medical Systems, Uppsala, Sweden) was inserted into the target coronary artery passed the borderline stenosis and used to record thermodilution curves and distal coronary pressure. Thermodilution curves were obtained in triplicate from a hand-held, 3-ml brisk $(<0.25 \mathrm{~s})$ injection of room temperature saline at baseline and at maximal hyperemia. Mean transit time at baseline and maximal hyperemia were derived from thermodilution curves. Simultaneous measurements of mean aortic pressure $\left(\mathrm{P}_{a}\right.$, by guiding catheter) and mean distal coronary pressure ( $\mathrm{P}_{d}$, by pressure wire) were also made in resting and maximal hyperemic states. Maximal hyperemia was achieved by a $140 \mu \mathrm{g} / \mathrm{kg} / \mathrm{min}$ intravenous infusion of adenosine. CFR was calculated from the ratio of baseline to hyperemic mean transit time. IMR was calculated from the ratio of the mean distal coronary pressure at maximal hyperemia divided by the inverse of hyperemic mean transit time. FFR was calculated by the ratio of $\mathrm{P}_{d} / \mathrm{P}_{a}$ at maximal hyperemia. Special features for demonstration of cases with fistulous communications are presented at cases.

Myocardium-selective videodensitometry. Angiograms for densitometric analysis at baseline (and maximal hyperemia) were recorded on an Innova 2000 ${ }^{\mathrm{TM}}$ (GE Healthcare, Chalfont St. Giles, Buckinghamshire, United Kingdom) system, in a way that phase-matched DSA can be performed on them $(16,17)$. This required the following criteria: 1$)$ motion of patient or table 
should be avoided; 2) patient should hold breath for the time of recording; 3) one contrast-free heart cycle should be recorded before injection of contrast material; 4) field of view is to be set to contain the whole supplied area of the vessel of interest. Standardized projections were chosen to minimize the superimposition of coronary arteries, veins and the aorta with the myocardium of interest. Left anterior descending coronary artery (LAD) and left circumflex (CX) coronary artery were recorded in lateral, while right coronary artery (RC) was recorded in a left anterior oblique $15^{\prime}$ projection. Constant quantity of nonionic contrast material $(6 \mathrm{ml})$ was injected for all angiograms by an automatic injector (Acist Medical Systems, Bracco, Milan) at a rate of $3 \mathrm{cc} / \mathrm{sec}$ in order to standardize the density of angiograms. Images were stored in $512 \times 512$-size, 8 -bit, grayscale, uncompressed format.

Phase-matched DSA angiograms were recorded on the same way in each patient with constant quantity contrast delivered, brightness, and stabilized acquisition parameters of the $\mathrm{X}$ ray imaging system $(16,17)$. The computerized method for myocardial perfusion assessment was based on the analysis of time-density curves (TDCs) measured over the infarction-related myocardial region of interest (ROI). Polygonal-shaped ROIs were selected by an experienced interventional cardiologist and covered the entire myocardial area at risk. Vesselness probability maps were calculated for each image frame. TDCs were calculated as average pixel value in the ROI, excluding pixels having a vesselness probability value $>0.08$. Frequencies higher than $0.6 \mathrm{~Hz}$ have been removed from the TDC to eliminate artifacts from cyclic heart contractions, and noise in image acquisition. Myocardial perfusion has a single-wave density signal around $0.1 \mathrm{~Hz}$; therefore it is still present on the filtered curve. Frequency filtering was performed using the Matlab 7.0 mathematical software. Maximal density of the TDC $\left(\mathrm{G}_{\max }\right)$ and time to reach maximum density ( $\mathrm{T}_{\max }$ ) were measured on the filtered curve. Myocardial perfusion was characterized by $G_{\max } / T_{\max }$ (Figure 1). TDCs were analyzed to obtain $\mathrm{G}_{\max } / \mathrm{T}_{\max }$ values, as described previously, at baseline as at hyperemia in some studies $(16,17)$. Maximal hyperemia, as per CFR, IMR, and FFR protocol was achieved by a $140 \mu \mathrm{g} / \mathrm{kg} / \mathrm{min}$ intravenous infusion of adenosine. Two angiograms were taken with identical parameters in both baseline and hyperemic state, and videodensitometric myocardium perfusion reserve was calculated from the ratio of hyperemic to baseline $\mathrm{G}_{\max } / \mathrm{T}_{\max }$. 

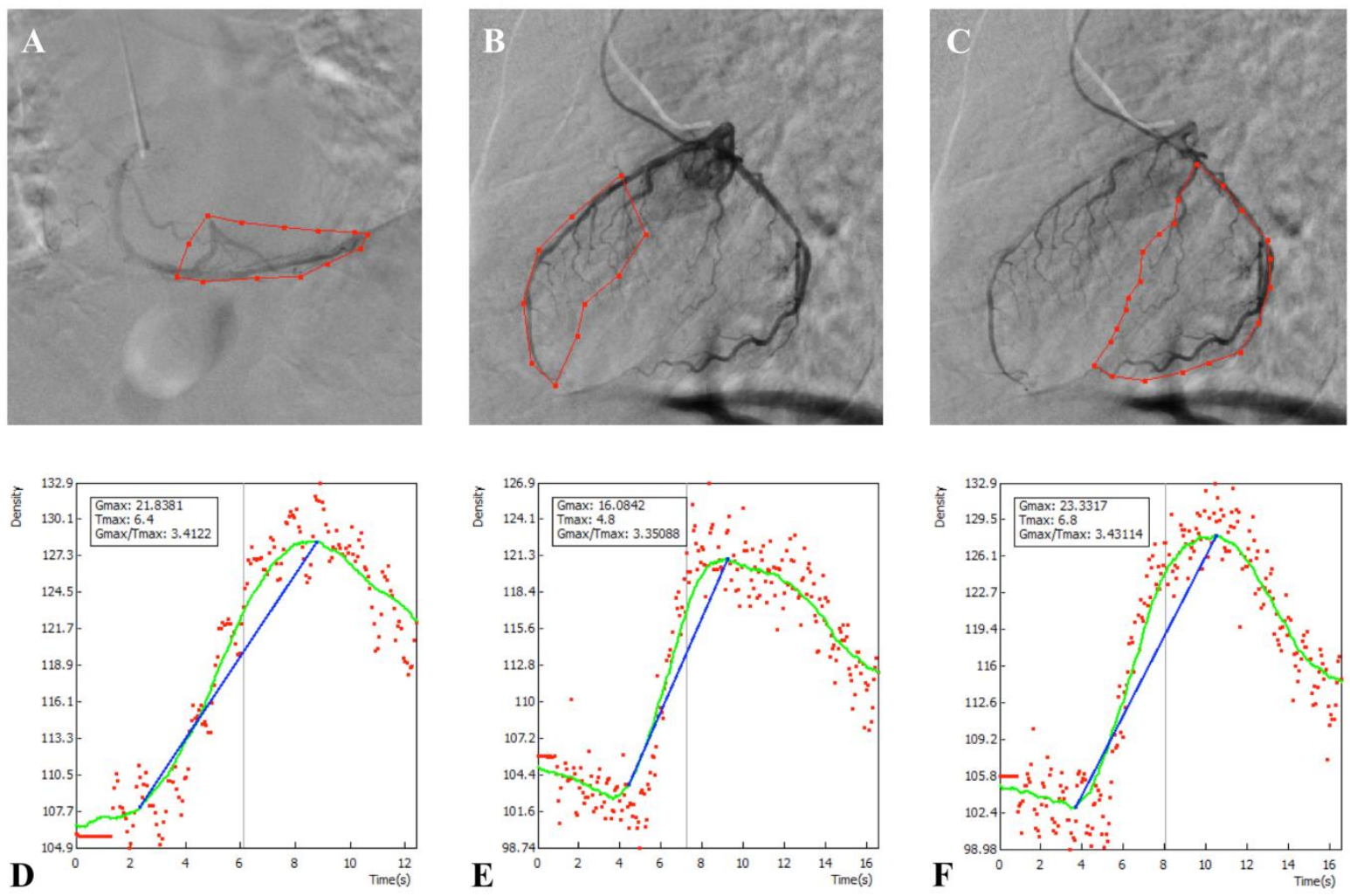

Figure 1 Digital subtraction angiographic images of the right coronary artery $(\mathrm{RC}, \mathrm{A})$, left anterior descending coronary artery (LAD, B) and left circumflex coronary artery $(\mathrm{CX}, \mathrm{C})$ are presented on the top panels. Time-density curves related to the above mentioned images are presented on lower panels $(\mathrm{D}, \mathrm{E}, \mathrm{F})$ together with maximum density of the time-density curve $\left(G_{\max }\right)$, the time to reach maximum density $\left(T_{\max }\right)$ and their ratio $\left(\mathbf{G}_{\max } / \mathbf{T}_{\max }\right)$.

Cardiac magnetic resonance imaging analysis. In some studies, for evaluation of late LV function (Figure 2) and myocardial infarction size (Figure 3), cardiac MRI was performed after percutaneous coronary intervention (PCI) using a 1.5 Tesla GE Signa ${ }^{\circledR}$ EXCITE $^{\circledR}$ MRI (GE Healthcare, Waukesha, Wisconsin, USA) equipment with a cardiac software package. 

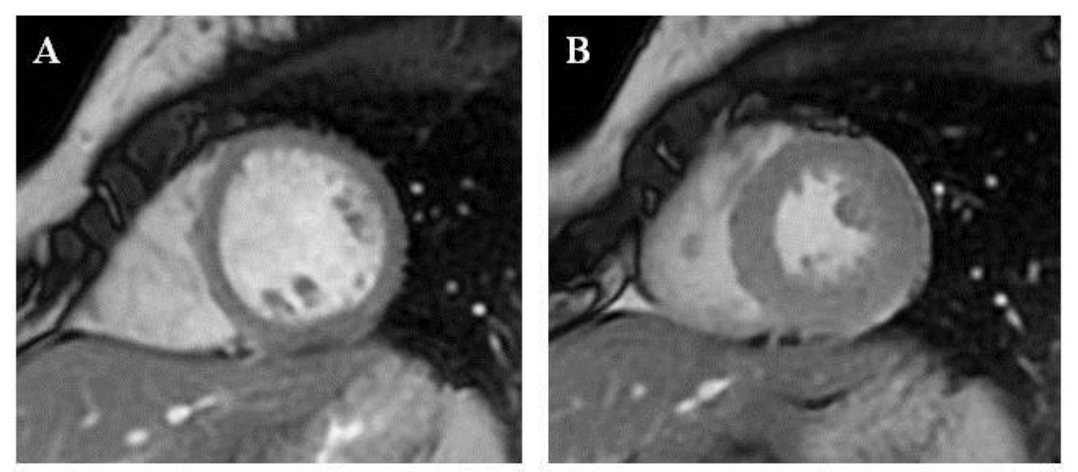

Figure 2 During magnetic resonance imaging on diastolic (A) and systolic (B) crosssectional images following detection of epicardial and endocardial contour diastolic and systolic left ventricular volumes, ejection fraction, stroke volume and mass could be calculated.

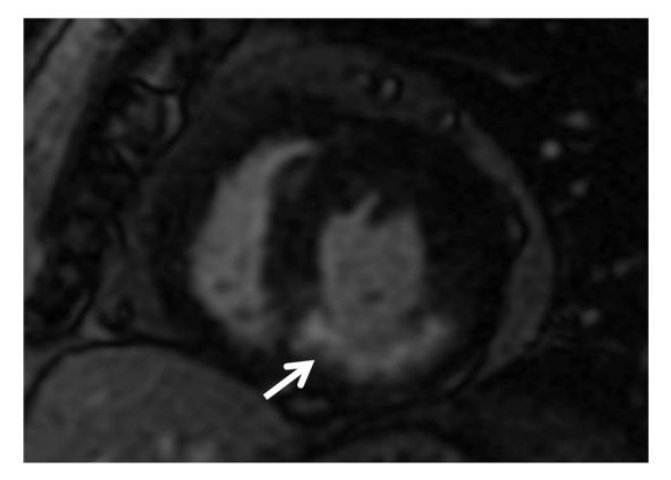

Figure 3 A magnetic resonance cross-sectional image of a patient with myocardial infarction is presented (see white arrow).

Patients were positioned in the supine position, with a cardiac 8-element phased-array coil placed over the thorax. Repeated breath-holds and electrocardiographic gating were applied to minimize the influence of cardiac and respiratory motion on data collection. 2D FIESTA sequence was performed, imaging parameters were as follows: repetition time, $3.6 \mathrm{~ms}$; echo time, $1.6 \mathrm{~ms}$; flip angle, $50^{\circ}$; field of view, 43 x $38.9 \mathrm{~cm}$; matrix, 224 x 224 . To cover the entire LV 8 to 12 consecutive slices of $8 \mathrm{~mm}$ in the short axis view were planned on the 4 chambers (gap, $0 \mathrm{~mm}$ ). Papillary muscles were considered as part of the LV cavity. The following LV paramteres were considered for functional assessment: LV end-diastolic and end-systolic volume (ESV), ejection fraction (EF), stroke volume and LV mass.

Myocardial loss index. In one study, late gadolinium enhancement MRI images were used for assessing infarcted myocardial regions. A single bolus dose of $0.15 \mathrm{mmol} / \mathrm{kg}$ of gadolinium 
DTPA was used in all cases, and late enhancement was considered present only if confirmed on both short-axis and matching long-axis myocardial locations. In order to have numerous values for lost myocardial tissue, coronary angiograms were analyzed and the location of occlusion was pinpointed and according to SYNTAX coronary segment analysis the supplied myocardial area was defined according to the recommendations of the American Society of Echocardiography (19). After the number of supplied segments was calculated each segment was analyzed on late gadolinium enhancement MRI and the transmural loss was calculated in each segment according to MRI data obtained of each segment. $0 \%$ loss of tissue meant 1, 25\% loss equaled $0.75,50 \%$ equaled $0.5,75 \%$ meant $0.25,100 \%$ translated to 0 . This way the viable tissue was defined for each supplied segment and the sum of each supplied segment analysis was divided by the number of supplied segment distal to the occlusion. The dividend was defined as the myocardial loss index (MLI) (lower MLI means higher myocardial tissue loss).

Percutaneous coronary intervention. In some studies PCI was performed. All patients received acetyl-salicilic acid (500 mg), clopidogrel $(600 \mathrm{mg}$ ) and at least $5000 \mathrm{IU}$ of unfractionated Na-heparine prior to PCI. Performance of PCI followed available guidelines (20). Bare metal stent (BMS) was used in all cases.

Statistical analysis. All statistical tests were performed with MedCalc software (MedCalc, Mariakerke, Belgium). Data are reported as mean \pm standard deviation. A value of $\mathrm{p}<0.05$ was considered to be statistically significant. Paired sample $t$ test was used where needed. Correlations were assessed by a Pearson's correlation coefficient. To establish the predictive power of $G_{\max } / T_{\max }$, receiver operator characteristic curves (ROCs) were constructed and area under the curve together with sensitivity and specificity values were created. 


\section{Results}

\subsection{Videodensitometric myocardial perfusion assessment}

\subsubsection{Validation of videodenzitometric myocardial perfusion assessment}

Study population. The present study comprised thirteen patients with borderline coronary artery stenosis (40\% to $70 \%$ diameter stenosis by visual assessment). All of them were admitted for elective coronarography after a positive stress test showing inducible ischemia. Borderline stenosis served as an indication for FFR measurement in all cases for functional evaluation of stenosis. For main risk factors of the patients, see Table 1.

Table 1. Clinical and demographic parameters of patients

Patients

Sample size (n)

Male gender (\%)

Age (years)

Diabetes mellitus (\%)

Hypercholesterolemia (\%)

Hypertension (\%)

Smoking (\%)
13

$8(62)$

$60.1 \pm 8.7$

$4(31)$

$9(70)$

$9(70)$

$4(31)$

Relationship between FFR and $\mathbf{G}_{\max } / \mathbf{T}_{\max }$. Of the 13 patients enrolled in the study videodensitometric and pressure wire measurements were conducted in 13 coronary arteries: 10 left anterior descending, 2 right coronary arteries and 1 circumflex artery with borderline coronary angiographic stenosis. The mean degree of diametric stenosis by visual assessment was $55 \pm 12 \%$. The corresponding mean FFR was found to be $0.86 \pm 0.12$ (Table 2). Of the 13 
coronary arteries 5 (all left anterior descending coronary artery) showed a FFR $<0.8$, in these patients successful stenting was performed. Measurements were not repeated after stenting. FFR showed no correlations with hyperemic $\mathrm{G}_{\max } / \mathrm{T}_{\max }(\mathrm{r}=-0.14, \mathrm{p}=0.66)$ and videodensitometric myocardium perfusion reserve $(r=-0.37, p=0.22)$.

Table 2. Parameters of coronary microvascular function and epicardial flow

\begin{tabular}{lcc}
\hline & At baseline & At hyperemia \\
\hline Blood pressure, systole (mm Hg) & $125 \pm 18$ & $108 \pm 20$ \\
Blood pressure, diastole (mm Hg) & $64 \pm 8$ & $52 \pm 16$ \\
Mean transit time (sec) & $0.89 \pm 0.44$ & $0.29 \pm 0.18$ \\
Index of microcirculatory resistance (U) & $78.06 \pm 44.03$ & $5.77 \pm 1.68$ \\
Gmax/Tmax (1/sec) & $3.76 \pm 1.28$ & \\
\hline Fractional flow reserve & & \\
Coronary flow reserve & \multicolumn{2}{c}{$0.86 \pm 0.12$} \\
Myocardium perfusion reserve & $3.53 \pm 1.84$ & \\
& & $1.60 \pm 0.42$ \\
\hline
\end{tabular}

Relationship between mean transit time and $\mathbf{G}_{\max } / \mathbf{T}_{\max }$. At baseline conditions mean transit time was $0.89 \pm 0.44 \mathrm{sec}$, and $\mathrm{G}_{\max } / \mathrm{T}_{\max } 3.76 \pm 1.28 / \mathrm{sec}$ (Table 2). During maximal hyperemia mean transit time decreased to $0.29 \pm 0.18 \mathrm{sec}$ and $\mathrm{G}_{\max } / \mathrm{T}_{\max }$ increased to $5.77 \pm 1.68 / \mathrm{sec}$ (Table 2). The improvement of $\mathrm{G}_{\max } / \mathrm{T}_{\max }$ at hyperemia proved to be significant compared to baseline ( $\mathrm{p}<0.0001$ ) (Figure 1). A significant correlation could be demonstrated between baseline mean transit time and baseline $\mathrm{G}_{\max } / \mathrm{T}_{\max }(\mathrm{r}=-0.70 \mathrm{p}=0.0076)$, and a trend could be demonstrated between hyperemic mean transit time and hyperemic $\mathrm{G}_{\max } / \mathrm{T}_{\max }(\mathrm{r}=-0.53, \mathrm{p}=0.0628)$. 
Relationship between IMR and $\mathbf{G}_{\max } / \mathbf{T}_{\max }$. Baseline and hyperemic IMR were found to be $78.06 \pm 44.03 \mathrm{U}$ and $18.86 \pm 11.00 \mathrm{U}$, respectively (Table 2). A significant correlation was found between baseline IMR and baseline $\mathrm{G}_{\max } / \mathrm{T}_{\max }(\mathrm{r}=-0.71, \mathrm{p}=0.0069)$, as well as between hyperemic IMR and hyperemic $\mathrm{G}_{\max } / \mathrm{T}_{\max }(\mathrm{r}=-0.72, \mathrm{p}=0.0058)$ (Figure 4).

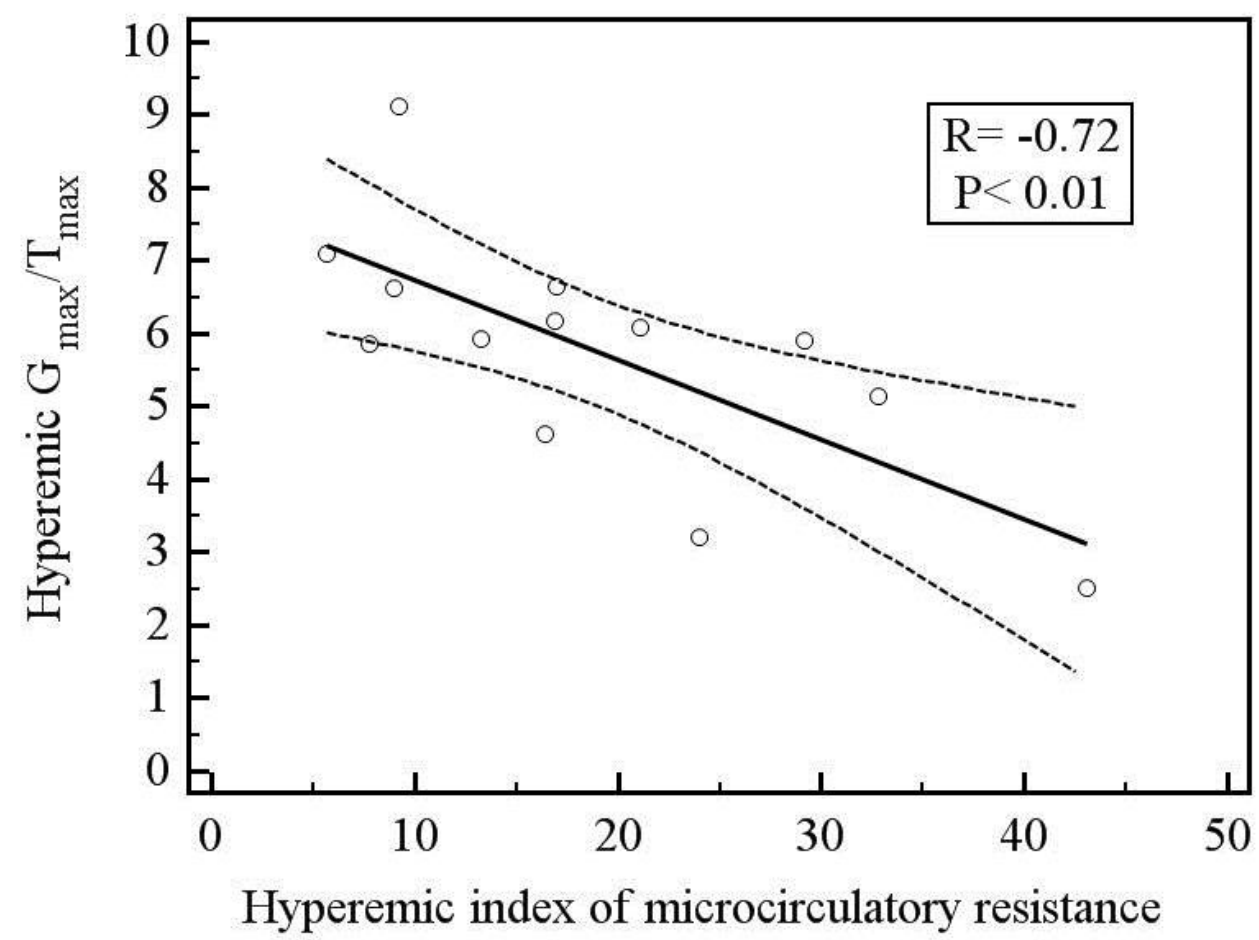

Figure 4 Correlation between hyperemic Gmax/Tmax and hyperemic index of myocardial resistance.

Relationship between CFR and $\mathbf{G}_{\max } / \mathbf{T}_{\max }$. Mean values of thermodilution-derived CFR proved to be $3.53 \pm 1.84$ and videodensitometric myocardium perfusion reserve $1.60 \pm 0.42$ (Table 2). A significant correlation was found between videodensitometric myocardium perfusion reserve and thermodilution-derived CFR $(\mathrm{r}=0.82, \mathrm{p}=0.0008)$ (Figure 5). 


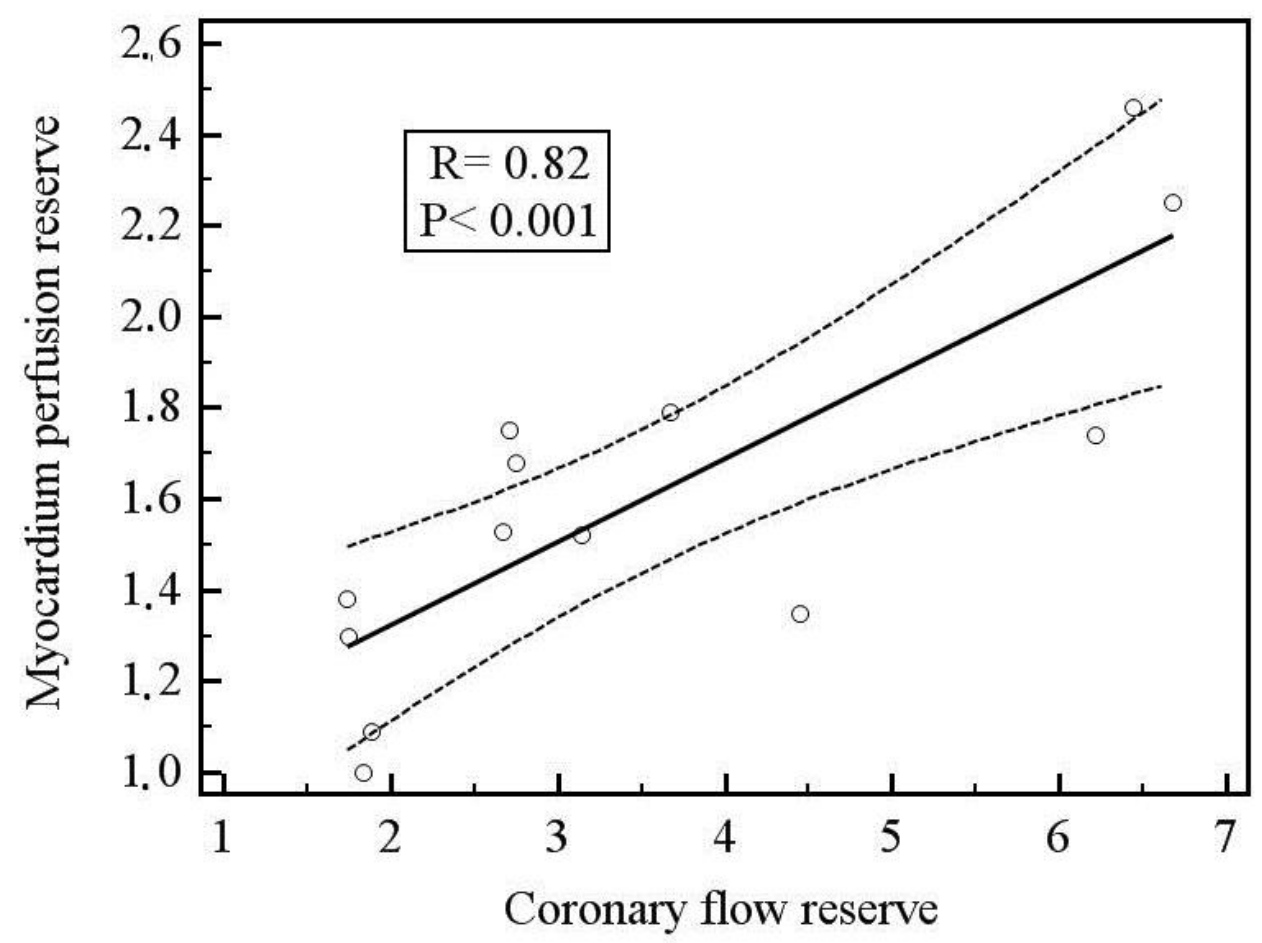

Figure 5 Correlation between thermodilution-derived coronary flow reserve and videodensitometric myocardium perfusion reserve.

4.1.2. Relationship between early myocardial reperfusion assessed by videodensitometry and late left ventricular function - Results following invasive treatment of acute myocardial infarction

Study population. The study comprised 25 patients. All of them were treated at the Division of Invasive Cardiology, Department of Cardiology, University of Szeged due to STEMI. During coronary angiography total occlusion could be demonstrated in one vessel in all cases. PCI with bare-metal stent implantation was performed in all subjects. Following PCI, coronary angiogram was recorded, on which blush parameters characterizing myocardial perfusion were determined offline. In all patients MRI examination was done to examine LV dimensions and function following $387 \pm 262$ days after STEMI. 
Clinical and demonsgraphic data. Clinical and demographic data of patients are presented in Table 3.

Table 3. Clinical and demographic data of patients with STEMI

\section{Data}

Patient number (n)

Males (\%)

Age (years)

Diabetes mellitus (\%)

Hypercholesterolaemia (\%)

Hypertension (\%)

Smoking (\%)

Previous myocardial infarction (\%)

Positive familiar anamnaesis (\%)

Weight (kg)

Height (m)

Body mass index $\left(\mathrm{kg} / \mathrm{m}^{2}\right)$
$18(72)$

$58.7 \pm 10.8$

$16(64)$

$16(64)$

$17(68)$

$2(8)$

$13(52)$

$85.0 \pm 20.6$

$169.8 \pm 10.2$

$29.1 \pm 5.7$

Coronary angiography results. Distribution of total occlusion in coronary arteries related to myocardial infarction and myocardial blush parameters measured following PCI on coronary angiogram with vs. without vessel masking are presented in Table 4. 
Table 4. Results of coronary angiography and densitometric measurements

Data

Results of coronary angiography

Significant one-vessel disease $(\%)$

$14(56)$

Significant two-vessel disease (\%)

Significant three-vessel disease $(\%)$

Place of infarction-related total occlusion

Left anterior descending coronary artery (\%)

Left circumflex coronary artery $(\%)$

Right coronary artery $(\%)$

Results of densitometric measurements

Gmax (without vessel masking)

$14.39 \pm 5.81$

Tmax (without vessel masking)

$4.71 \pm 1.03$

Gmax/Tmax (without vessel masking) (1/s)

$3.04 \pm 1.13$

Gmax (with vessel masking)

$12.18 \pm 4.96$

Tmax (with vessel masking)

$4.32 \pm 0.89$

Gmax/Tmax (with vessel masking) (1/s)

$2.79 \pm 0.97$

Results of MRI examinations. MRI-derived LV data are summarized in Table 5. 
Table 5. Magnetic resonance imaging-derived left ventricular data following late after myocardial infarction

\section{Data}

Left ventricular end-diastolic volume $(\mathrm{ml})$

$144.5 \pm 33.6$

Left ventricular end-systolic volume (ml)

$69.8 \pm 31.6$

Left ventricular ejection fraction $(\%)$

$53.6 \pm 12.6$

Left ventricular stroke volume (ml)

$74.6 \pm 17.5$

Left ventricular mass $(\mathrm{g})$

$121.9 \pm 36.1$

Correlations. Significant correlations could be demonstrated between LV-EF and $\mathrm{G}_{\max }(\mathrm{r}$ $=0.40, \mathrm{p}=0.05)$ and $\mathrm{G}_{\max } / \mathrm{T}_{\max }(\mathrm{r}=0.41, \mathrm{p}=0.04)$ with vessel masking. Similar correlations could be demonstrated between LV-ESV) and $\mathrm{G}_{\max }(\mathrm{r}=-0.37, \mathrm{p}=0.05)$ and $\mathrm{G}_{\max } / \mathrm{T}_{\max }(\mathrm{r}=0 .-42$, $\mathrm{p}=0.04$ ). If measurements were performed without vessel masking, LV-EF correlated with $\mathrm{G}_{\max } / \mathrm{T}_{\max }(\mathrm{r}=0.39, \mathrm{p}=0.05)$, and LV-ESV with $\mathrm{G}_{\max }(\mathrm{r}=0.38, \mathrm{p}=0.05)$, and with $\mathrm{G}_{\max } / \mathrm{T}_{\max }(\mathrm{r}$ $=0.49, \mathrm{p}=0.01)$.

ROC analysis. During ROC analysis cut-off value of $\mathrm{G}_{\max } / \mathrm{T}_{\max } \geq 2,17$ measured with vessel masking proved to have a prognostic value to predict half-year $\geq 50 \%$ LV-EF with $88 \%$ sensitivity [95\%-s confidence intervallum (CI) 64-99\%] and $86 \%$ specificity (95\% CI 42 100\%) (Figure 6). 


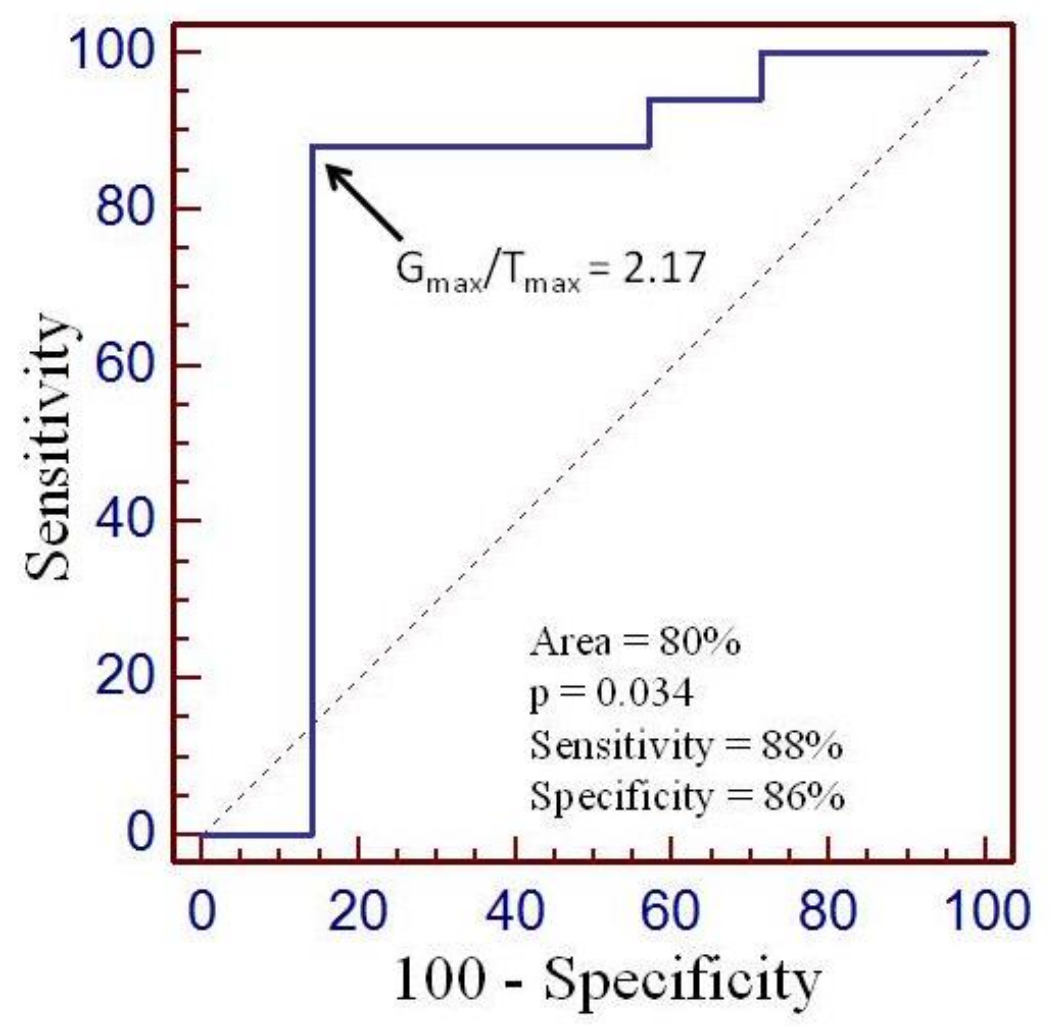

Figure 6. Receiver operating characteristic analysis confirmed that Gmax/Tmax $\geq 2.17$ is suitable for prediction of late (appr. one-year) $\geq 50 \%$ left ventricular ejection fraction with 88 sensitivity and $86 \%$ specificity

\subsubsection{Prediction of myocardial tissue loss by quantitative densitometric myocardial blush parameters following ST-elevation myocardial infarction}

Study population. The present study comprised 29 consecutive patients with STEMI, who had undergone PCI. The following inclusion criteria was used during enrollment of patients:

(1) acute ST elevation in contiguous leads on 12-lead ECG

(2) pain-to-balloon time $<12 \mathrm{~h}$

(3) total occlusion of the proximal segment of one of the three main coronary arteries, and

(4) capability of the patient to cooperate with the recording of the coronary angiograms.

Patients who were unconscious or showed signs of cardiogenic shock or had visible collateral circulation in the infarction-related myocardial region were excluded from the study. For evaluation of late LV myocardial infarction size, cardiac MRI was performed $376 \pm 254$ days after PCI. 
Clinical and demographic data. Clinical data of the patient population are summarized in Table 6.

Table 6. Baseline characteristics and clinical data of patients

\begin{tabular}{lc}
\hline & Data \\
\hline Number of patients & 29 \\
Age (years) & $59.1 \pm 10.9$ \\
Male gender $(\%)$ & $21(72)$ \\
Diabetes mellitus $(\%)$ & $7(24)$ \\
Hypertension $(\%)$ & $20(69)$ \\
Hypercholesterolaemia $(\%)$ & $18(62)$ \\
Smoking habits $(\%)$ & $19(65)$ \\
Previous myocardial infarction $(\%)$ & $3(10)$ \\
Family history $(\%)$ & $15(52)$ \\
Weight (kg) & 85.120 .2 \\
Height (cm) & 169.810 .1 \\
Body mass index $\left(\mathrm{kg} / \mathrm{m}^{2}\right)$ & $29.2 \pm 5.6$ \\
\hline
\end{tabular}

The most important baseline laboratory findings and medications applied are presented in Table 7. 
Table 7. The most important laboratory findings and medications applied of patients

\section{Data}

\section{Medicines}

Acethyl-salicylic acid / Clopidogrel (\%)

ACE inhibitor / ARB (\%)

$8(28)$

Beta-blocker $(\%)$

Statin $(\%)$

Nitrate $(\%)$

\section{Laboratory findings}

Total cholesterol level (mmol/l) $5.00 \pm 21.35$

LDL cholesterol level (mmol/l) $3.08 \pm 1.13$

HDL cholesterol level (mmol/l) $1.22 \pm 0.44$

Triglycerid level (mmol/l)

$1.54 \pm 1.10$

Karbamide (mmol/l)

7.112 .61

Creatinine (umol/l)

$76.83 \pm 23.71$

Haematocrit

$0.40 \pm 0.04$

Haemoglobin

$134.38 \pm 12.53$

Abbreviations: $\mathrm{ACE}=$ angiotensine - converting enzyme, $\mathrm{ARB}=$ angiotensine receptor blocker. $\mathrm{HDL}=$ high density lipoprotein, $\mathrm{LDL}=$ low density lipoprotein

Coronary angiographic, videodensitometric and MRI data. Distribution of STEMI-related coronary arteries is demonstrated in Table 8 . 
Table 8. Results of coronary angiography and densitometric measurements

Data

\title{
Coronary angiography
}

Significant one -vessel disease (\%)

Significant two-vessel disease $(\%)$

Significant three-vessel disease (\%)

\section{Place of infarction-related total occlusion}

Left anterior descending coronary artery $(\%)$

Left circumflex coronary artery $(\%)$

Right coronary artery (\%)

\section{Results of densitometric measurements}
$\mathrm{G}_{\max }$ (without vessel masking)
$13.56 \pm 6.51$
$\mathrm{T}_{\max }$ (without vessel masking)
$4.84 \pm 1.39$
$\mathrm{G}_{\max } / \mathrm{T}_{\max }$ (without vessel masking) (1/s)
$2.86 \pm 1.27$
$\mathrm{G}_{\max }$ (with vessel masking)
$11.53 \pm 5.64$
$\mathrm{T}_{\max }$ (with vessel masking)
$4.37 \pm 1.11$
$\mathrm{G}_{\max } / \mathrm{T}_{\max }$ (with vessel masking) (1/s)
$2.64 \pm 1.12$
No of regions supplied by the infarction-related artery
$5.86 \pm 1.33$

\begin{abstract}
Abbreviations: $\mathrm{G}_{\max }=$ maximum density of time-density curve, $\mathrm{T}_{\max }=$ time to reach maximum density of time-density curve
\end{abstract}

All patients eligible for the study had undergone successful revascularization achieving TIMI 3 flow and residual stenosis less than 30\%. Multivessel disease (MVD) was present in 14 cases (48\%), where significant non-infarction-related lesions were treated $8 \pm 1$ weeks after the index procedure. Bare metal stents were implanted at the index procedure in all cases. Clinically driven repeated revascularization (target lesion revascularization) was performed with drugeluting stents in 3 cases $(10 \%)$ during the follow-up. Myocardial blush parameters as 
assessed by videodensitometry on the closing coronary angiograms following PCI with vs. without vessel masking are presented in Table 4. Mean MRI-derived MLI proved to be $0.65 \pm$ 0.23 .

Correlations. Significant correlations could be demonstrated between MLI and $\mathrm{G}_{\max }(r=0.36$, $\mathrm{p}=0.05)$ and $\mathrm{G}_{\max } / \mathrm{T}_{\max }(\mathrm{r}=0.40, \mathrm{p}=0.03)$ using vessel masking (Figure 7). Similar correlations were found for the 16 patients with same occlusion site (RCA), as a homogeneous group $(\mathrm{r}=$ $0.32, \mathrm{p}=0.05$ and $\mathrm{r}=0.38, \mathrm{p}=0.05$, respectively).
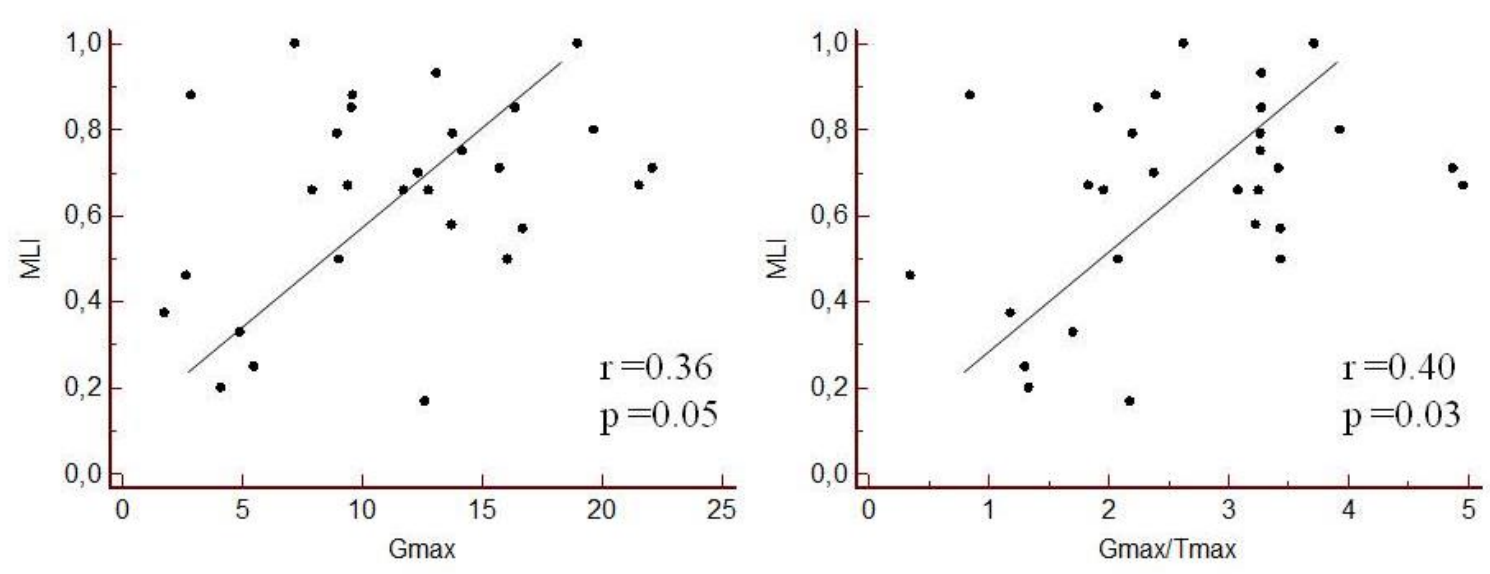

Figure 7. Significant correlations could be demonstrated between MLI and $G_{\max }$ and $\mathbf{G}_{\max } / \mathbf{T}_{\max }$

ROC analysis. Using ROC analysis, $\mathrm{G}_{\max } / \mathrm{T}_{\max }<2.17$ predicted best MLI=0.3, 0.4, 0.5 and 0.6 with good sensitivity and specificity data, while $\mathrm{G}_{\max } / \mathrm{T}_{\max }<3.25$ proved to have a prognostic role in the prediction of MLI=0.7 (Figure 8). 

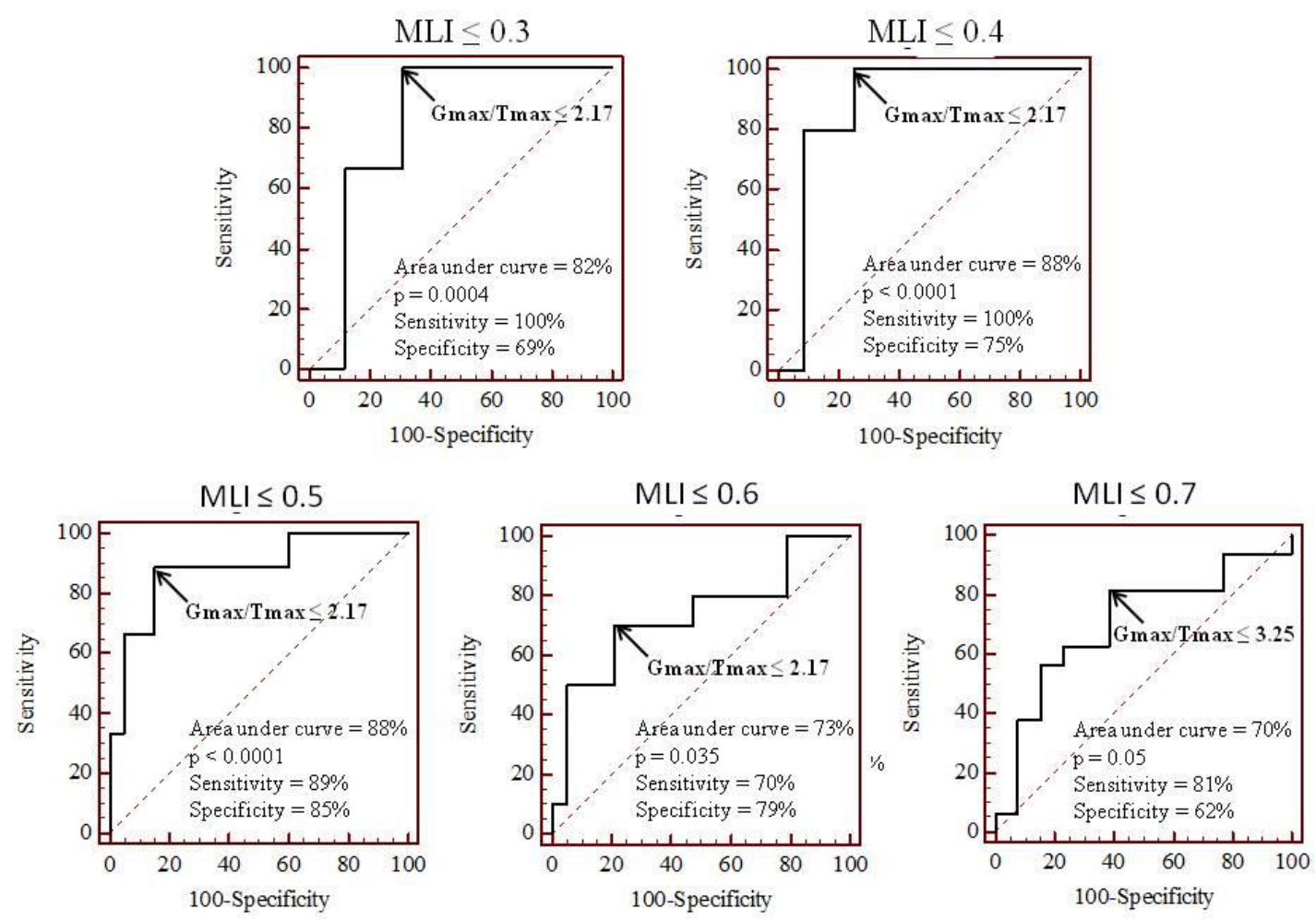

Figure 8 Receiver operating characteristic analysis confirmed that $G_{\max } / T_{\max }<2.17$ predicted best myocardial loss index $(M L I)=0.3,=0.4,=0.5$ and $=0.6$ with good sensitivity and specificity data, while $G_{\max } / T_{\max }<3.25$ proved to have a prognostic role in the prediction of $\mathrm{MLI}=\mathbf{0 . 7}$.

\subsubsection{Videodensitometric time-density curve change after alcohol septal ablation of obstructive hypertrophic cardiomyopathy}

A 35-year-old female patient with obstructive hypertrophic cardiomyopathy, causing New York Heart Association Class III symptoms, underwent alcohol septal ablation $(21,22)$. Before and after ablation, coronary angiograms were recorded on the left anterior descendent artery, and subsequently phase-matched digital subtraction angiograms have been performed on the recordings off-line. The recently developed computerized method for estimation of myocardial perfusion, based on the analysis of the TDC, was used to assess myocardial blush over a selected myocardial region of interest representing the area supplied by the ablated septal branch. The ratio of Gmax (defined as maximal amplitude of the TDC) and Tmax (defined as the time to reach Gmax) was reduced after alcohol ablation compared with pre-procedural levels indicating reduced perfusion in the ablated septal area. This new method may allow evaluation of myocardial perfusion parameters, and may assist to judge the success of alcohol ablation in hypertrophic cardiomyopathy (Figure 9). 

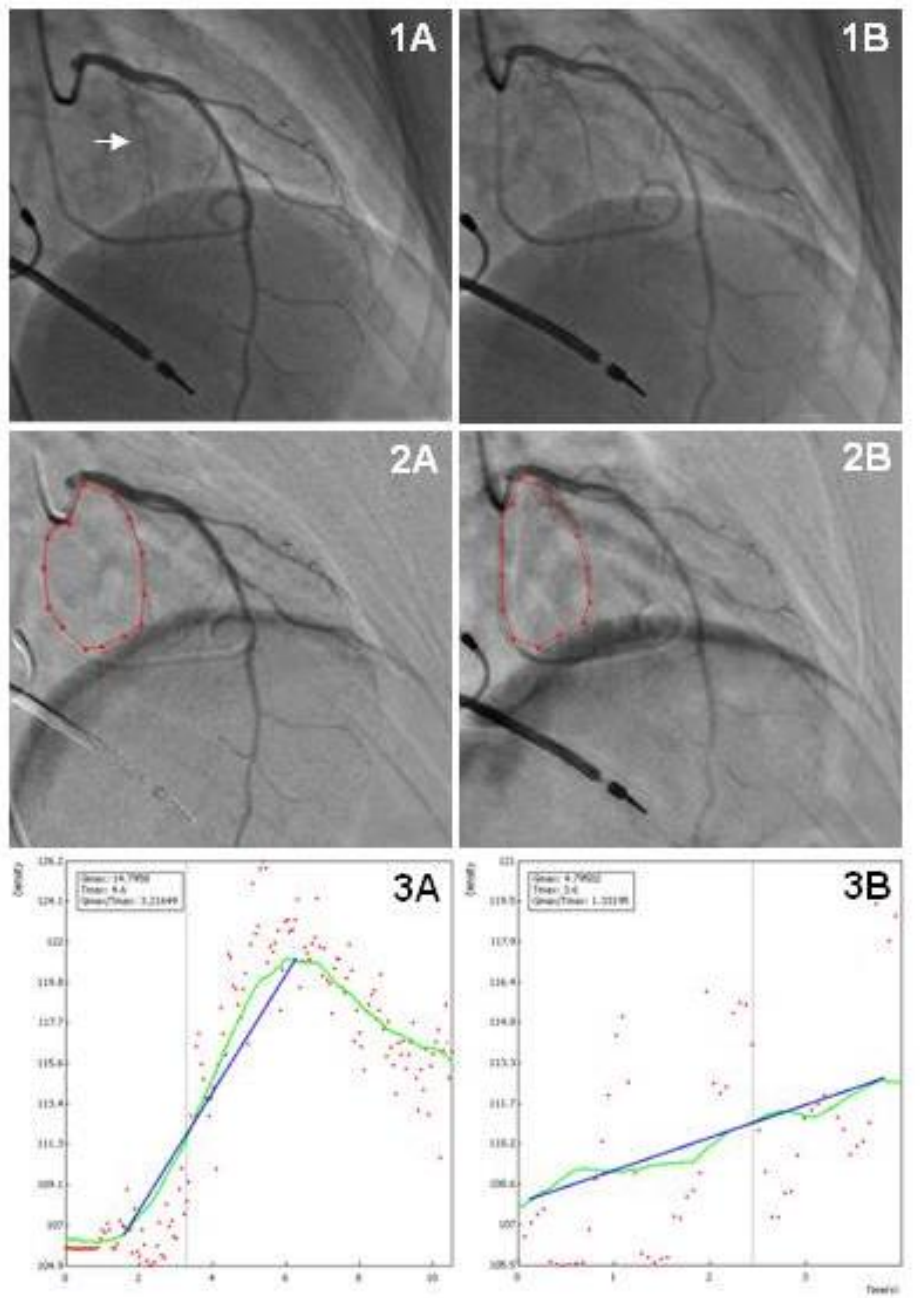

Figure 9. Angiographic, digital subtraction angiographic and videodensitometric changes after alcohol ablation in obstructive hypertrophic cardiomyopathy. Insert 1. Coronary angiographic images of the left anterior descending coronary artery shown from cranialright anterior oblique orientation in a HOCM patient before (1A) and after (1B) alcohol ablation. Arrow indicates a sub-branch of the first septal perforator artery which was ablated during the procedure. The absence of the branch is evident on the post-procedure angiogram (1B). Insert 2. Digital subtraction angiographic images, shown from identical orientation to Insert 1 , before $(2 \mathrm{~A})$ and after $(2 \mathrm{~B})$ alcohol ablation. The region of interest (ROI), drown around in red, represents the area supplied by the ablated branch. Myocardial blush is represented by greyish opacification of the microvasculature, which is seemingly reduced after ablation (2B). Insert 3. Time-density curves based on videodensitometric evaluation of density in region of interest from Insert 2 indicating myocardial perfusion before $(3 \mathrm{~A})$ and after $(3 \mathrm{~B})$ alcohol ablation. The rise and fall of density ( $y$ axis) as a function of time ( $x$ axis) is represented by a green curve (time-density curve, TDC). The maximal amplitude of TDC is defined as $\mathbf{G}_{\max }$, while the time to reach $G_{\max }$ is defined as $T_{\max }$. Both values were automatically computed and their ratio $\left(G_{\max /}\right.$ $T_{\max }$ ) was used as a parameter of myocardial perfusion changes. The ratio of $G_{\max } / T_{\max }$ was reduced after alcohol ablation compared to pre-procedural levels (3.21 vs. 1.33) indicating reduced perfusion in the ablated septal area. 


\subsection{Functional estimation of coronary fistulas}

\subsubsection{Multiple coronary fistulas originating from all major coronary arteries}

A 49-year-old man was referred for cardiac catheterization because of atypical chest pain. The electrocardiogram showed broader $\mathrm{P}$ waves, $\mathrm{rSr}$ ' in leads III-aVF and J point elevation in leads V1-3. In leads III-aVF there was a slight ST depression with biphasic T waves, and otherwise positive T waves. Physical examination revealed a slight systolic murmur (grade 1/6) over the apex. Transthoracic echocardiography demonstrated $58 \mathrm{~mm}$ enddiastolic and $40 \mathrm{~mm}$ endsystolic LV diameters with a slight LV hypertrophy, 50\% LV-EF and diffuse hypokinesia. The SPECT thallium revealed a persistent perfusion defect from the posterior wall to the apex and a smaller perfusion defect on the anterior septum with a transient component. Cardiac catheterization demonstrated contrast high velocity emptying from the distal parts of all three major vessels into the LV cavity through multiple small coronary arterio-ventricular connections, resulting in immediate opacification in the left heart chamber (Figures 10-11).
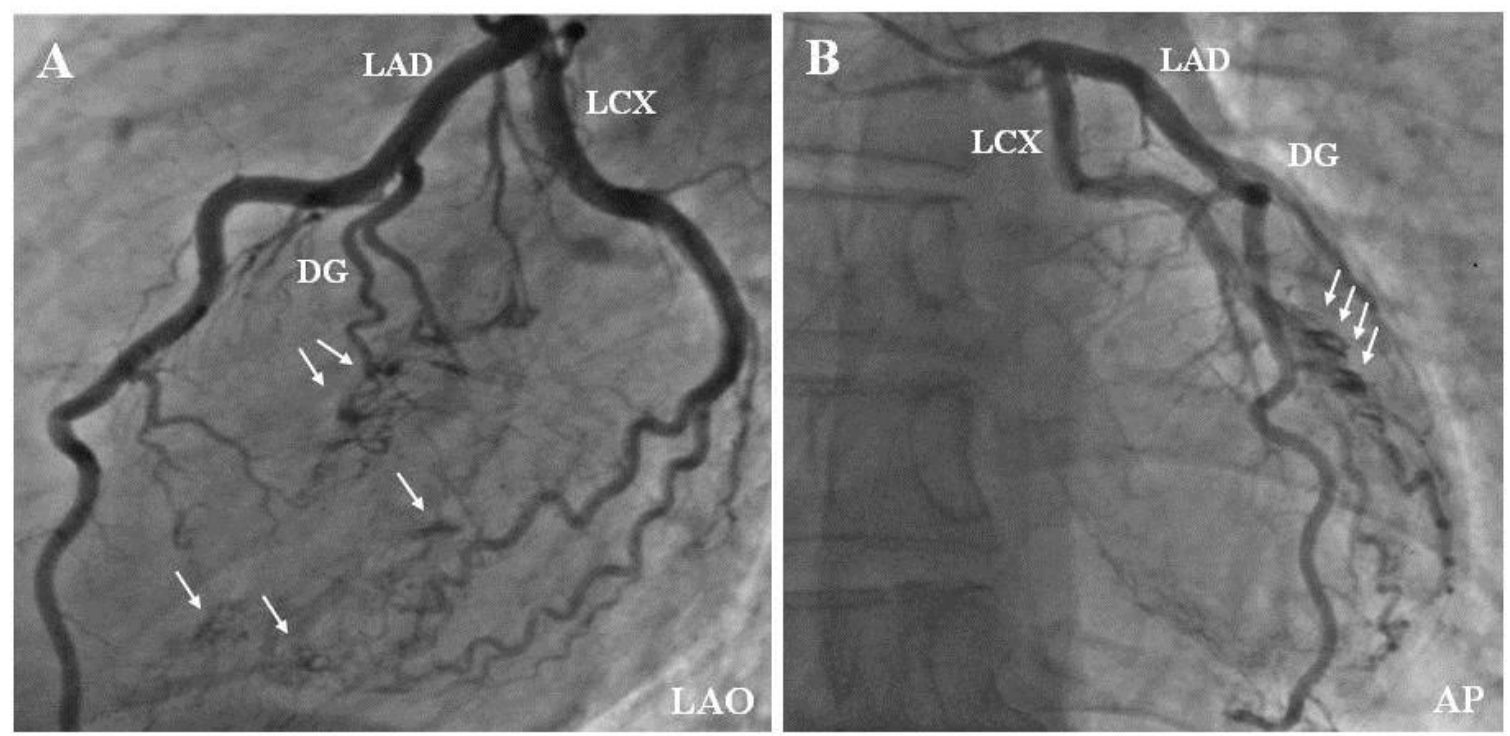

Figure 10. Left anterior oblique projection of the left coronary system showing contrast opacification to the left ventricular cavity through numerous micro-fistulas originating from the left anterior descending (LAD), diagonal (DG) and left circumflex coronary (LCX) arteries (see white arrows) (Fig 10A). On the anteroposterior projection of the left coronary system contrast media opacifications are also appeared (Fig 10B). 


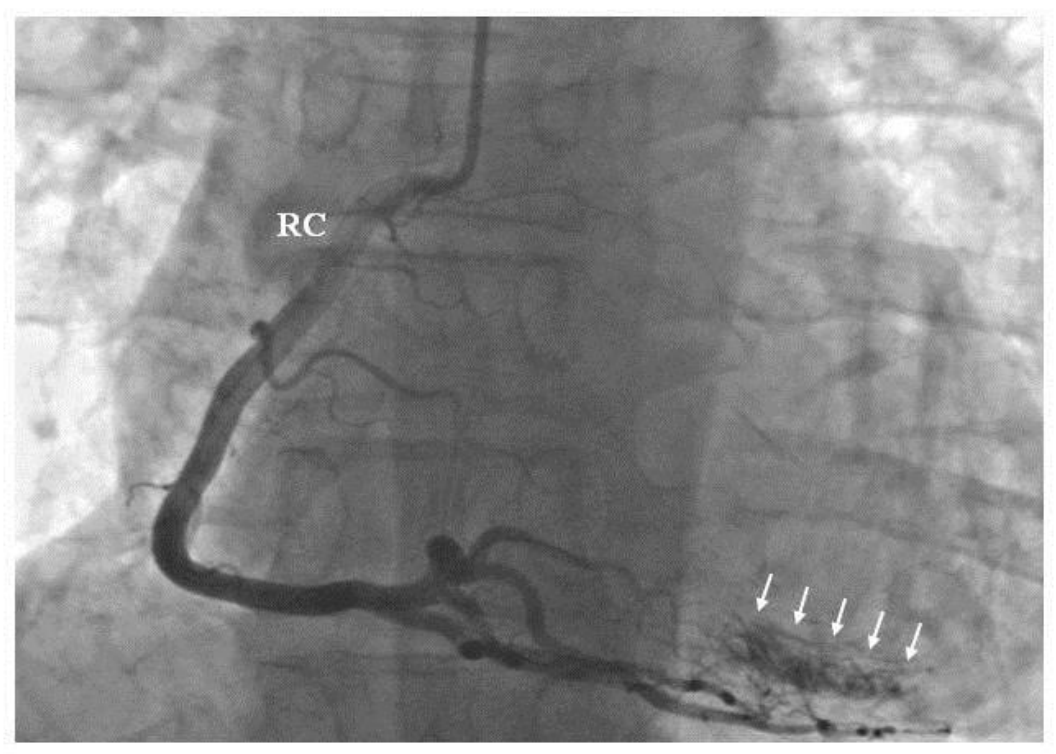

Figure 11. The right coronary artery $(\mathrm{RC})$ is shown in the right anterior oblique view. Multiple fistulas towards to the left ventricular cavity are visible showing contrast material transported from the distal part of the right coronary artery (see white arrows).

On cardiac MRI, akinesia was present at the apex and at the distal part of the lateral wall with a calculated LV-EF of $38 \%$ and with LV hypertrophy especially at the apex. However, due to lower image resolution, MRI could not confirm major fistulas originating from the coronary arteries. FFR and CFR measurements were performed to gain more data on the potential functional aspects of these fistulas. FFR measured the distal blood flow, reproducing the coronary steal phenomenon. CFR was obtained to measure the potential change of resistance in the microvascular bed. The results were consequent, LAD-FFR was 0.76, LAD-CFR was 3.2, the CX-FFR was 0.81 , CX-CFR could not be measured for technical reasons, RC-FFR measurement resulted in 0.91, and RC-CFR was found to be 1.6 (23-25).

As a conclusion, the decision was made that neither surgery nor catheter closure would be performed in this case. Due to available literature, in which patients' symptoms were controlled partially with beta-blocker therapy, a conservative therapy was continued $(26,27)$. 
4.2.2. Functional assessment of a left coronary-pulmonary artery fistulas by coronary flow reserve

A 71-year-old man presented with atypical chest pain. Physical examination revealed a continuous murmur (1/6) over the apex. Electrocardiogram showed sinus rhythm with no noteworthy abnormalities. Transthoracic echocardiography indicated good ejection fraction with no wall motion abnormalities, hypertrophic left ventricle, slightly enlarged left atrium and grade I mitral regurgitation. A turbulent flow could be demonstrated in the distal part of the left main coronary artery (LM) and in the proximal LAD by Doppler echo. Coronary angiography was performed but neither LM nor LAD stenosis could be confirmed; however, fistulous communications with a stronger tube-like fistula was present originating from the proximal LAD emptying into the main pulmonary artery (PA) (Figures 12 and 13) $(28,29)$.
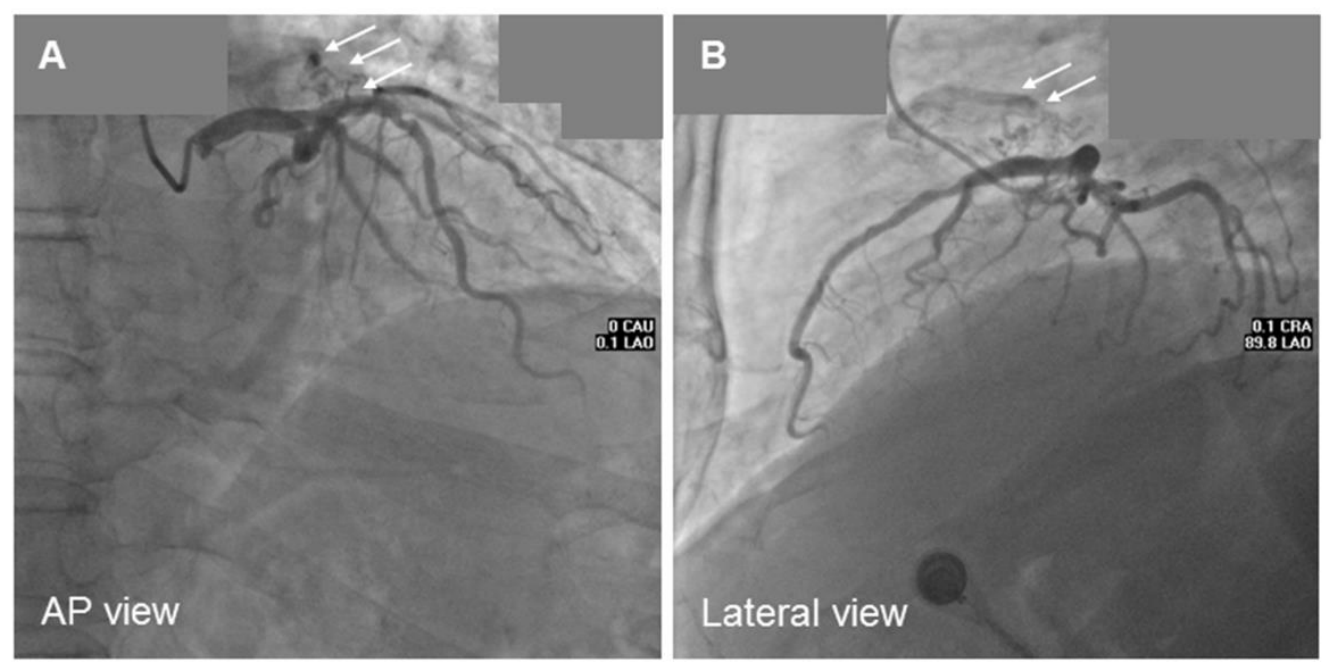

Figure 12. Anteroposterior projection of the left coronary system showing contrast opacification towards the main pulmonary artery through numerous micro-fistulas and one stronger tube-like fistula originating from the proximal part of the left anterior descending artery (LAD) (A, see white arrows). Lateral view of the left coronary system showing contrast media transported towards the main pulmonary artery through microfistulas and one stronger channel originating from the proximal LAD (B, see white arrows). 

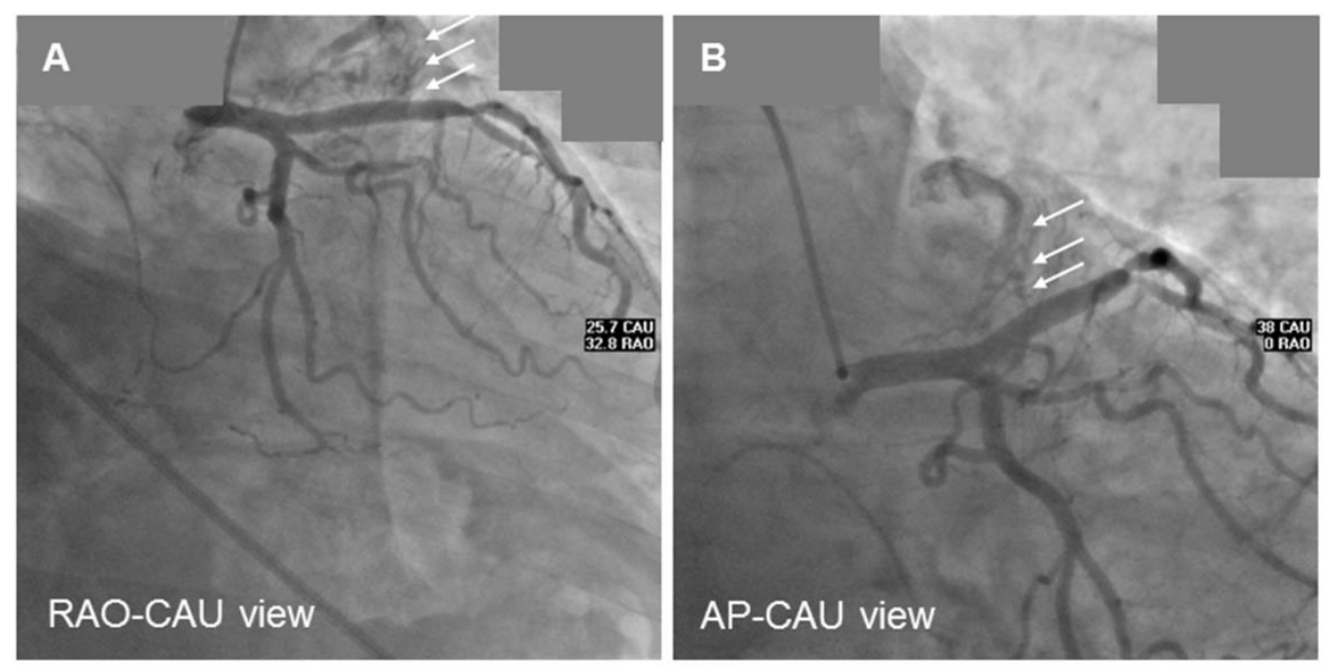

Figure 13. Right anterior oblique-caudal view of the left coronary system with fistulas apparent towards the main pulmonary artery originating from the proximal part of the left anterior descending artery (LAD) (A, see white arrows). Anteropostero-caudal view of the left coronary system showing numerous microfistulas and one stronger tube-like fistula taking off of the proximal LAD with contrast material transported towards the main pulmonary artery (B, see white arrows).

The pulmonary-to-systemic flow ratio (Qp/Qs) was 1.1/1. Data were obtained from oxygen saturation samples from systemic arterial blood, left atrial/pulmonary venous blood, pulmonary artery, and caval vein/right heart samples. The SPECT thallium stress test demonstrated discrete persistent perfusion defects on the anterior and posterior walls with no transient component. In agreement with the coronary angiography finding, computer tomography angiography revealed a fistula of $1 \mathrm{~mm}$ diameter. In order to assess the functional importance of these fistulous communications, FFR and CFR measurements were performed in the donor artery with a Pressure Wire System (St. Jude Medical, Minneapolis, MN, USA). Measurements were performed with administration of $50 \mathrm{U} / \mathrm{kg}$ heparin. To minimize vasoaction and measurement variability, $200 \mu \mathrm{g}$ of intracoronary (i.c.) nitroglycerin was also injected $3 \mathrm{~min}$ before the sensor guide-wire was advanced. The amount of i.c. adenosine was administered going up from 200 $\mu \mathrm{g}$ to $240 \mu \mathrm{g}$ for each FFR measurement. For CFR assessments, $20 \mathrm{mg}$ of papaverine was administered i.c. The LAD-FFR was found to be 0.86, LAD-CFR was 1.56. The CX-FFR and CX-CFR were 0.97 and 2.33, respectively. In view of these results and anatomic features, neither covered stent deployment nor coil embolization was performed. 


\section{Discussion}

\subsection{Videodensitometric myocardial perfusion assessment}

\subsubsection{Validation of videodenzitometric myocardial perfusion assessment}

In the present study significant correlations could be demonstrated between videodensitometric myocardium perfusion reserve and thermodilution-derived CFR, as well as between hyperemic videodensitometric $G_{\max } / T_{\max }$ and hyperemic IMR in stable angina patients. These findings suggest that computer-assisted myocardium selective videodensitometry may be applied in the cardiac catheterization laboratory as a mean for interrogating and quantifying microcirculatory function of coronary arteries.

The need for assessment of coronary microvascular dysfunction in the catheterization laboratory and current available techniques. Despite rapid evolvement of noninvasive techniques for investigation of coronary microcirculatory disorders as contrast echocardiography (12,30), cardiac MRI (31), multislice CT (31), myocardial perfusion scintigraphy (32), PET (33), and combined techniques (34), the quantitative assessment of coronary microcirculation in the catheterization laboratory remains desirable to date. The reasons for this are the following: 1) angiography remains the golden standard for ruling out epicardial stenosis (35); 2) a large proportion of patients still present without adequately interpretable prior functional noninvasive testing (36); 3) reperfusion therapy in acute myocardial infarction has shifted to the catheterization laboratory, where immediate evaluation of therapeutic success and further outcome is of advantage (37).

Current available techniques include invasive measurement by CFR and IMR, which can prove to be time, expense and instrumentation consuming. Angiographic visual assessment by myocardial blush grade and TIMI myocardial perfusion grade on the other hand is only routinely applied to study the microcirculation during reperfusion in STEMI. Myocardium selective videodensitometric assessment of perfusion as the above mentioned methods utilizes the indicator dilution principle where the input function is an intracoronary injection of $\mathrm{X}$-ray contrast and the output observable is opacification of the myocardium supplied (38). Perfusion is numerically assessed by the ratio of maximal density and the time to reach maximum density of the time-density curves in regions of interest on X-ray coronary angiograms $(15,16)$. This 
method allows for objective and quantitative assessment, is cost effective without further need for coronary instrumentation. It could be interpretable in specific non-acute coronary syndrome settings as well with more sensitivity and specificity compared to myocardial blush grade and TIMI myocardial perfusion grade (15).

Relationship between $\mathbf{G}_{\max } / \mathbf{T}_{\max }$ and coronary flow reserve. CFR is defined as the ratio of peak hyperemic to baseline flow. A drop in CFR may indicate loss of response to hyperemic stimuli due to coronary microvascular dysfunction in the absence of significant coronary artery disease or a decreased resting microcirculatory resistance in consequence of a flow-limiting epicardial coronary artery stenosis. At hyperemia a rise in epicardial coronary flow is accompanied by an increase in myocardium perfusion, which theoretically can be observed as a rise in $\left(\mathrm{G}_{\max } / \mathrm{T}_{\max }\right)$ compared to baseline. This theory was justified in our experiment as we found a significant elevation of hyperemic $G_{\max } / T_{\max }$ value compared to baseline $G_{\max } / T_{\max }$ in all patients. The ratio of hyperemic to resting perfusion $\left(\mathrm{G}_{\max } / \mathrm{T}_{\max }\right)$ could be interpreted as videodensitometric myocardium perfusion reserve similarly to the concept of CFR creating an index representing the state of microcirculation like CFR. Underlining this concept others before us found a decline of videodensitometric myocardium perfusion reserve in hypertensive patients known to suffer from coronary microvascular dysfunction compared to controls, however did not attempt to study a possible correlation of myocardium perfusion reserve with other validated methods (39). In the current publication we go further by reporting a significant correlation between the validated method of thermodilution-derived CFR and myocardium perfusion reserve suggesting comparable clinical benefit (Figure 5).

Relationship between $\mathbf{G}_{\max } / \mathbf{T}_{\max }$ and IMR. Recently IMR, a novel marker of coronary microvascular function has been introduced, showing superior reproducibility and less hemodynamic dependence then CFR (6). It is derived from the directly measured distal coronary pressure and mean transit time at hyperemia and is validated in animal models to correlate with true microvascular resistance (4). Theoretically, coronary microvascular dysfunction detected by IMR as rise of microvascular resistance at maximum hyperemia can also be assessed by hyperemic $\mathrm{G}_{\max } / \mathrm{T}_{\max }$ as an impediment of contrast penetration into the myocardium leading to a flattened rise slope of the hyperemic time-density curve and decreased values of $G_{\max } / T_{\max }$. Indeed, in the current study we report a significant correlation between hyperemic $\mathrm{G}_{\max } / \mathrm{T}_{\max }$ and hyperemic IMR (Figure 4). 
Possible independence of $\mathbf{G}_{\max } / \mathbf{T}_{\max }$ from epicardial stenosis. Severe epicardial stenosis leads to a distal pressure and flow drop (observed as a rise in mean transit time) distal to the lesion. In the current study population with borderline lesions this phenomenon is prominent at hyperemia only (40). The rise in hyperemic mean transit time will lower the CFR value independently and additionally to the underlying coronary microvascular dysfunction obscuring data interpretation (38). In the case of hyperemic IMR (calculated as hyperemic distal pressure $\mathrm{x}$ hyperemic mean transit time) the drop of distal pressure caused by epicardial stenosis is hypothesized to counterbalance the rise of mean transit time leaving IMR unchanged (5). In this study as expected we found no significant correlations between FFR, solely dependent on epicardial stenosis severity and any of the videodensitometric derived parameters representing myocardial perfusion. A significant correlation observed between mean transit time and $\mathrm{G}_{\max } / \mathrm{T}_{\max }$ at baseline was found to be a nonsignificant trend at hyperemia, whereas the significant correlation observed at baseline between IMR and $\mathrm{G}_{\max } / \mathrm{T}_{\max }$ was also significant at hyperemia. The correlation of hyperemic $\mathrm{G}_{\max } / \mathrm{T}_{\max }$ to hyperemic IMR rather than to hyperemic mean transit time in this special patient subset suggests that hyperemic $G_{\max } / T_{\max }$ like IMR may be unaffected by epicardial stenosis. This does not contradict previous findings of correlation between videodensitometric myocardium perfusion reserve and CFR which in this special population seems to be mainly driven by significant correlation of baseline $G_{\max } / T_{\max }$ and mean transit time. To clarify this matter further prospective investigations are warranted in larger groups of patients with clearly significant epicardial disease effecting baseline flow as well as in groups entirely free of epicardial coronary artery disease.

Limitation section. Computer-assisted myocardium selective videodensitometric perfusion assessment has been under constant improvement as technological progress permitted. Further investigations however are needed to solve the remaining problem of static region of interest areas. Large areas can result in variable results due to inhomogenous distribution of contrast material. On the other hand, small static area selection is difficult for the whole image sequence because of the cyclic motion of myocardium caused by the heart beating. A possible improvement to tackle this problem and improve precision could be motion tracking of myocardial regions. All procedures were done by a single operator using automatic contrast injector using standardized flow rate and amount. Timing of injection however was not synchronized to the phase of the heart cycle, which may contribute to the limited level of correlations in our results (41). This problem can be eliminated by the use of an 
electrocardiogram triggered injector. Further inherent limitations include current commercial unavailability of the method which renders large scale clinical use.

\subsubsection{Relationship between early myocardial reperfusion assessed by videodensitometry and late left ventricular function - Results following invasive treatment of acute myocardial infarction}

Regarding to our results it could be stated, that densitometry-derived $\mathrm{G}_{\max } / \mathrm{T}_{\max }$ measured on coronary angiograms characterizing myocardial reperfusion immediately following invasive intervention of STEMI shows relationship with late LV function: the higher post-PCI myocardial blush, the lower LV-ESV and the higher LV-EF during an average half-year followup. It was also confirmed by analysis, that densitometric parameters have prognostic power to predict late $\mathrm{LV}$ function $(\geq 50 \% \mathrm{LV}-\mathrm{EF})$.

The presented videodensitometric measurement is based on a software, which has been partially developed at our department $(16,17)$. Previously, several tools have been developed, with which myocardial perfusion could be quantitated on coronary angiogram: myocardial myocardial blush grade (MBG) measures maximal contrast density (13), while TIMI myocardial perfusion grade (TMPG) characterize the clearance dye of contrast from the microvasculature (14). Over the presented quantitative densitometric measurements other applications have also been developed and introduced $(15,37,42)$. The presented videodensitometric methodology has been validated by IMR and CFR as demonstrated in chapter 5.1.1.

Presentation of the results of our first studies with this software in patients with STEMI have been done in 2009 (16,17). Relationship could be demonstrated between densitometric perfusion alterations related to infarction and early indicators of myocardial reperfusion (16). It could be confirmed that vessel masking improves sensitivity of videodensitometric myocardial perfusion assessments (17). Based on these results later vessel masking was always applied during videodenszitometric measurements. With present study, evaluation of LV size and function was done by MRI due to its best ,gold standard” image quality (previously echocardiography was used). The aim of the present research was to examine late functional recovery which could explain why MRI was performed almost one-year after infarction. In another study it has been confirmed, that $G_{\max } / T_{\max }$ calculated over supplied myocardial areas of all three coronary arteries shows correlations with TIMI frame count (TFC) in patients wuth stable clinical condition with negativ coronary angiography (43). TFC in a simple, reproducible, 
quantitative and objective method to characterize epicardial flow not only in patients with myocardial infarction, but also in stable patients with microcirculatory dysfunction. During TFC frame count is calculated on a coronary angiogram, while contrast agent „runs over” a certain coronary artery. It has also been confirmed that videodensitometric perfusion is reduced in patients with hypertension and aortic stenosis by $\mathrm{G}_{\max } / \mathrm{T}_{\max }$ calculated for all coronary arteries $(44,45)$. One another studies highlighted the opportunity of the videosdensitometric assessment of the success of percutaneous transluminal septal myocardial ablation in HOCM (46).

Our results are in agreement with previous findings described by other working groups. Following successful angioplasty due to myocardial infarction tissue reperfusion improves by time, which is accompanied by improvent of LV function (47). In another study MBG $\geq 2$ was found to be one of the best predictor of LV functional recovery following STEMI (48). Regarding to Bax et al CFR was found to be one of the best prognostic marker of LV functional recovery following anterior infarction (49). However, further studies are warranted in larger patient population to confirm, whether $G_{\max } / T_{\max }$ measured by our method shows similar context, as well.

Limitation section. Over previously mentioned limitations it should also been considered that the effect of different drugs and other disorders on study outcome was not evaluated and low number of patients was evaluated. Myocardial blush parameters measured for different infarction-related coronary artery were not calculated separately, as well.

\subsubsection{Prediction of myocardial tissue loss by quantitative densitometric myocardial blush parameters following ST-elevation myocardial infarction}

To the best of authors' knowledge this is the first time when feasibility of the recently developed videodensitometric method has been demonstrated in clinical circumstances to predict lost myocardial tissue level following STEMI at almost 1-year follow-up. Moreover, significant correlation could be detected between extent of myocardial infarction as expressed by MLI and densitometric $\mathrm{G}_{\max } / \mathrm{T}_{\max }$ myocardial blush parameters. Traditionally, normalized epicardial blood flow means success after recanalization of the occluded artery in patients with STEMI. TIMI grade 3 epicardial coronary blood flow could be achieved in more than $90 \%$ in experienced invasive cardiology centers. However, TIMI grade 3 flow is not equivalent to good myocardial tissue level perfusion thus long-term good clinical outcome and decreased mortality, which has been well described in 1990s by different imaging modality studies, such 
as MRI (50) and radionuclide studies (51). Poor microcirculatory perfusion after primary PCI results in larger enzymatic infarction size, lower residual LV-EF, higher mortality, and higher incidence of major adverse cardiac events in a long-term follow-up (52). To date cardiac MRI is considered as the gold standard in the assessment of left ventricular function and size and transmurality of myocardial infarction (53). Therefore we decided to compare the relationship between myocardial perfusion parameters as assessed after PCI in STEMI patients by densitometry on coronary angiograms and late MRI-derived characteristics of myocardial damage. Low densitometry-derived $\mathrm{G}_{\max } / \mathrm{T}_{\max }$ seems to have a prognostic role in prediction lost myocardial tissue at 1 year-follow-up. Comparison with previous videodensitometric studies are presented in previous chapters.

Limitation section. Over previously demonstrated limitations 48 percent of patients had MVD. It is important to be considered that collateral systems associated with MVD could affect myocardial perfusion assessments, as well.

\subsubsection{Videodensitometric time-density curve change after alcohol septal ablation of obstructive hypertrophic cardiomyopathy}

Regarding to guidelines, at this moment contrast echocardiography is used in routine clinical practice for the evaluation of success of alcohol septal ablation in HOCM. With our case usefulness of videodensitometric assessment of perfusion abnormalities caused by alcohol septal ablation in a HOCM patient has been presented. The methodology is easy to perform, eather at the same time invasive procedure. However, further studies in larger patient HOCM patient population are required to confirm our findings.

\subsection{Functional estimation of coronary fistulas}

\subsubsection{Multiple coronary fistulas originating from all major coronary arteries}

Coronary fistulas to one of the cardiac chambers are infrequent anomalies and usually are found unexpectedly (54). In a large clinical study including 126,595 patients, coronary fistulas were found in only $0.17 \%$ of patients undergoing cardiac catheterization and only $0.05 \%$ were multiple or large size fistulas (54). Multiple fistulas communicating between coronary arteries and left heart chambers are extremely rare, especially those emptying into the LV (26). 
We presented a case with multiple and diffuse coronary artery-LV communications. Although multiple arterio-ventricular fistulas are very infrequent anomalies, angina pectoris and myocardial infarction can occur in the absence of atherosclerotic coronary artery disease (54). The majority of patients are asymptomatic, but coronary steal, signs of ischemia and fatal arrhythmias can be present in some cases. The most frequent symptoms are dyspnea, shortness of breath and angina (55), but may present as endocarditis (56), myocardial infarction or death (57). For diagnosing this phenomenon, coronary angiography is the gold standard.

In the present case, coronary angiography showed multiple fistulae arising from the distal parts of all major coronary vessels, providing immediate opacification in the LV cavity. Partially, because of the immediate opacification in the LV cavity, it seems reasonable to think that these microfistulas are not the so-called 'Thebesian veins', which definition is: 'Numerous small valveless venous channels, opening directly into the chambers of the heart from the capillary bed in the cardiac wall,,enabling a form of collateral circulation unique to the heart'. If these venous vessels exist, they primarily empty into the right atrium and right ventricle. If they drain into the left heart chambers, it contributes to right to left shunt of deoxygenated blood. 'Thebesian veins' would also have a somewhat delayed appearance of contrast into the target chamber. In the present case, the examinations performed including coronary angiography do not support the existence of these venous communications.

Unfortunately, for functional assessment, publications are not available in patients with multiple microfistulas. It seems reasonable to think that FFR and CFR could be adequate methods. While the epicardial vessels mainly serve as conductance channels for blood flow, the intramural vessels not only distribute blood flow within the myocardium, but also have distinctive functions for the coronary blood flow control. Coronary resistance is controlled by these small arteries and arterioles. In 'normal coronary arteries', there is a negligible pressure loss along the length of the coronary artery even at maximum hyperemia. In case of an epicardial stenosis, distal coronary pressure will decrease due to the resistance of the stenosis. The distal pressure is the actual perfusion pressure for the myocardial territory supplied by the stenotic coronary artery. In case of a 'not normal' coronary artery, as in the patient we presented, it would seem logical to think that not a stenosis, but multiple microfistulas emptying into the LV at maximum hyperaemia could cause a significant steal. For this reason we assume that FFR measurement would be a good tool to diagnose the coronary steal phenomenon in such patients. For FFR and CFR measurements PressureWire was used (Radi Medical Systems, Reading, MA, USA). The measurement was performed with intravenous (iv.) heparin 50 units/kg administered beforehand. To minimize vasomotion and measurement 
variability, 200 micrograms ( $\mu \mathrm{g})$ intracoronary (ic.) nitroglycerin was also given 5 minutes before the sensor guide wire was advanced. For the FFR measurement, $120 \mu \mathrm{g}$ adenosine was administered into the LAD and CX and $80 \mu \mathrm{g}$ for the RC. In the present case, FFR values in the RC and CX were 0.91 and 0.81 showing no impairment of flow in the distal part of the vessels, while LAD-FFR was 0,76 , which can be considered as a borderline value.

In our case invasive CFR measurements were also performed. As it is known, coronary resistance is controlled by small arteries and arterioles. CFR measures the capacity of the twocomponent system of coronary artery and supplied vascular bed to achieve maximal blood flow in response to a given hyperemic stimulation. The variability of CFR in unobstructed arteries is due to multiple factors such as vasoconstrictor, neurological or humoral influences, endothelial dysfunction, and extravascular compression of intramural vessels or, as in the present case multiple microfistulas emptying into the LV. During CFR measurements, $20 \mathrm{mg}$ ic. papaverine was administered for the $\mathrm{LAD}$ and $15 \mathrm{mg}$ papaverine ic. bolus for the RC. CFR in the LAD was 3.2, which is in the normal range and 1.6 for the $\mathrm{RC}$, which is an abnormal value. These microfistulas, as well as the proven LV hypertrophy can also contribute to the abnormal CFR in the territory supplied by the RC.

For this unique abnormality of the coronary vessels, not enough experience is available to decide whether invasive or surgical strategy, or the conservative approach would result in a better outcome for these patients. The anatomic defect may be corrected by surgery $(55,58)$ or percutaneously with coils or stent grafts (59). In a series of 14 patients described by Liu et al., 6 were treated surgically (58). One of them died in the postoperative period, but not from a cardiac cause. The other 5 were asymptomatic for five years after surgery. In the remaining 8 cases, after 5 years of follow-up, 4 continued with the initial clinical status and the other 4 patients complained of progression of symptoms. Today, one case of sudden death was associated with coronary fistulas. Satoh et al. demonstrated sudden cardiac death in a young Chinese patient with a RC fistula to a markedly hypertrophied LV. Autopsy confirmed microscopic evidence of myocardial ischemia (57).

\subsubsection{Functional assessment of a left coronary-pulmonary artery fistulas by coronary flow reserve}

The majority of patients with coronary artery fistulas have no symptoms, but dyspnea, congestive heart failure, angina pectoris, endocarditis, arrhythmia, or myocardial infarction may be present $(28,29)$. The non-invasive diagnosis of such fistulas is often difficult; therefore 
coronary angiography is currently the standard method of choice for the diagnosis of this phenomenon $(25,28,29,60,61)$. In cases of fistulous communications from the coronary tree the flow in the donor vessel can be compromised, especially in the presence of a proximal fistulous channel. In normal coronary arteries, there is no apparent pressure loss along the length of the coronary artery. In case of a stenosis, the distal coronary pressure decreases due to the resistance of the stenosis; however, perfusion pressure can be possibly lost via fistulas as well. It has been postulated that FFR may be feasible for functional severity assessment of coronary fistulas $(60,61)$. In this case a low FFR indicates a "pseudo-stenosis" of the anatomically normal vessels.

The shunt blood flow under resting conditions can provide useful extra information only if the shunt ratio is above $1.5(28,29)$. At maximum hyperemia, coronary steal can be manifested especially if the donor vessel supplies the territory of a dominant vessel. Harle et al. demonstrated that temporary occlusion of the fistula results in normalized FFR in the donor vessel; thus it was assumed that FFR measurement is a feasible means of diagnosing the functional severity in patients with a possible coronary steal (61).

It has been proved by simultaneous FFR and CFR determinations in patients with chronic total occlusion that a coronary steal through the collateral vessels influenced the functional severity of the disease in the donor vessel (62). In our patient, however, the case was completely different because the donor artery supplied an extracardiac compartment, i.e. the pulmonary circulation, in which the blood flow supposedly did not increase under the adenosine effect. The slightly decreased LAD-FFR might be explained by the turbulence at the origin of the fistula, which may have resulted in some impediment of the flow. An angiographically undetectable non-significant proximal LAD lesion may also have explained this difference.

Coronary resistance is controlled by arterioles and small arteries. The absolute CFR is the ratio of the maximum hyperemic to the basal mean coronary flow velocity in the target vessel. The CFR expresses the capacity of a two-component system of a coronary artery and the supplied vascular bed to achieve maximum blood flow in response to a given hyperemic stimulation (25). In the present case, the LAD-CFR was remarkably below the cutoff value of 2, while the CX-CFR was normal. This phenomenon can be explained by the fact that a significant fraction of the blood is diverted from the distal LAD into the pulmonary circulation by the collaterals, and this flow was not affected by the i.c. papaverine injection. Hereby the effective increase of the myocardial flow in the distal LAD stayed behind that of the CX artery. In other words, the relative decrease of CFR in the LAD reflected the relative flow in the fistula compared to the fraction effectively supplying the myocardial territory of the vessel. An 
essential limitation of this explanation is that the flow of the proximal and distal LAD and furthermore that of the pulmonary circulation was not directly measured. However, this deficiency resulted from the thermodilution method of CFR measurement that we applied. There are numerous factors that contribute to the fact that CFR cannot be utilized in clinical practice directly. The CFR values even in normal coronary arteries can be diverse, but if the value exceeds $15 \%$, it is considered to be significant as in the case presented. In the case presented the CX-CFR value was normal; therefore we could rule out other humoral, neurological factors and endothelial dysfunction for the abnormal LAD-CFR result.

It cannot yet be stated whether an invasive or surgical strategy or a conservative approach would result in a better outcome for these patients. The anatomic defect may be corrected surgically (28) or percutaneously with coils or covered stents $(63,64)$. Though the decrease of CFR in the LAD denoted a remarkable steal to the pulmonary circulation, in consideration of the missing evidence of myocardial ischemia, and the potential complications of surgical ligation or intervention we proceeded with medical therapy $(29,63)$. 


\section{Conclusions (new observations)}

Videodensitometric $\mathrm{G}_{\max } / \mathrm{T}_{\max }$ measurement seems to be a promising method to assess the myocardial microcirculatory resistance in patients with stable angina referred to coronary angiography. It may prove to be a low-cost, easily obtainable alternative method to the thermodilution-derived CFR and IMR measurements.

Relationship could be demonstrated between densitometric $\mathrm{G}_{\max } / \mathrm{T}_{\max }$ and cardiac MRI-derived late LV function following STEMI.

Selective myocardial perfusion quantitative measurement method is feasible and can serve as a good predictor of myocardial tissue loss level after STEMI and revascularization therapy.

A new numerical objective index - Myocardial Loss Index (MLI) shows great potential to quantify lost myocardial tissue through the course of STEMI.

Videodensitometric myocardial perfusion assessment on coronary angiograms can be used for quantitative evaluation of the success of alcohol septal ablation in hypertrophic obstructive cardiomyopathy

FFR and CFR can be a useful tool to assess the functional severity of patients presenting with fistulous communications between coronary arteries and other structures of the heart or blood vessels.

Thermodilution CFR measurement can allow a functional evaluation of coronary-pulmonary fistulas 


\section{References}

1. Camici PG, Crea FN. Coronary microvascular dysfunction. N Engl J Med 2007; 356: 830-840.

2. Knaapen P, Camici PG, Marques KM., Nijveldt R, Bax JJ, Westerhof N, Götte MJ, Jerosch-Herold M, Schelbert HR, Lammertsma AA, van Rossum AC. Coronary microvascular resistance: methods for its quantification in humans. Basic Res Cardiol 2009; 104: 485-498.

3. Kern MJ. Coronary physiology revisited: practical insights from the cardiac catheterization laboratory. Circulation 2000; 101: 1344-1351.

4. Fearon WF, Balsam LB, Farouque HM, Caffarelli A, Robbins RC, Fitzgerald PJ, Yock PG, Yeung AC. Novel index for invasively assessing the coronary microcirculation. Circulation 2003; 107: 3129-3132.

5. Aarnoudse W, Fearon WF, Manoharan G, Geven M, van de Vosse F, Rutten M, De Bruyne B, Pijls NH. Epicardial stenosis severity does not affect minimal microcirculatory resistance. Circulation 2004; 110: 2137-2142.

6. Ng MK, Yeung AC, Fearon WF. Invasive assessment of the coronary microcirculation: superior reproducibility and less hemodynamic dependence of index of microcirculatory resistance compared with coronary flow reserve. Circulation 2006; 113: 2054-2061.

7. De Bruyne B, Pijls NH, Kalesan B, Barbato E, Tonino PA, Piroth Z, Jagic N, MöbiusWinkler S, Rioufol G, Witt N, Kala P, MacCarthy P, Engström T, Oldroyd KG, Mavromatis K, Manoharan G, Verlee P, Frobert O, Curzen N, Johnson JB, Jüni P, Fearon WF; FAME 2 Trial Investigators. Fractional flow reserve-guided PCI versus medical therapy in stable coronary disease. N Engl J Med 2012; 367: 991-1001.

8. Cabrera-Rodríguez LO, Peix AT, Padrón KM, Chacón D, Carrillo R, Fernández Y, Mena E. Prognostic value of gated SPECT after reperfusion for acute myocardial infarction. MEDICC Rev 2013; 15: 20-25.

9. Rienmüller T, Baumgartner C, Handler M, Makarenko V, Ourednicek P, Krestinich IM, Zhorzholiani ST, Rienmüller R, Bockeria L. Quantitative estimation of left ventricular myocardial perfusion based on dynamic CT scans. Biomed. Tech. (Berl) (in press)

10. Bratis K, Mahmoud I, Chiribiri A, Nagel E. Quantitative myocardial perfusion imaging by cardiovascular magnetic resonance and positron emission tomography. J Nucl Cardiol 2013; 20: 860-870. 
11. Arumugam $\mathrm{P}$, Tout $\mathrm{D}$, Tonge C. Myocardial perfusion scintigraphy using rubidium- 82 positron emission tomography. Br Med Bull 2013; 107: 87-100.

12. Ito H. Myocardial contrast echocardiography after myocardial infarction. Curr Cardiol Rep 2012; 14: 350-358.

13. van't Hof AW, Liem A, Suryapranata H, Hoorntje JC, de Boer MJ, Zijlstra F. Angiographic assessment of myocardial reperfusion in patients treated with primary angioplasty for acute myocardial infarction: myocardial blush grade. Zwolle Myocardial Infarction Study Group. Circulation 1998; 97: 2302-2306.

14. Gibson CM, Cannon CP, Murphy SA, Ryan KA, Mesley R, Marble SJ, McCabe CH, Van De Werf F, Braunwald E. Relationship of TIMI myocardial perfusion grade to mortality after administration of thrombolytic drugs. Circulation 2000; 101: 125-130.

15. Korosoglou G, Haars A, Michael G, Erbacher M, Hardt S, Giannitsis E, Kurz K, FranzJosef N, Dickhaus H, Katus HA, Kuecherer H. Quantitative evaluation of myocardial blush to assess tissue level reperfusion in patients with acute ST-elevation myocardial infarction: incremental prognostic value compared with visual assessment. Am Heart J 2007; 153: 612-620.

16. Ungi T, Ungi I, Jónás Z, Sasi V, Lassó A, Zimmermann Z, Forster T, Palkó A, Nemes A. Myocardium selective densitometric perfusion assessment after acute myocardial infarction. Cardiovasc Revasc Med 2009; 10: 49-54.

17. Ungi T, Zimmermann Z, Balázs E, Lassó A, Ungi I, Forster T, Palkó A, Nemes A. Vessel masking improves densitometric myocardial perfusion assessment. Int $\mathbf{J}$ Cardiovasc Imaging 2009; 25: 229-236.

18. Pijls NH, De Bruyne B, Smith L, Aarnoudse W, Barbato E, Bartunek J, Bech GJ, Van De Vosse F. Coronary thermodilution to assess flow reserve: validation in humans. Circulation 2002; 105: 2482-2486.

19. Lang RM, Bierig M, Devereux RB, Flachskampf FA, Foster E, Pellikka PA, Picard MH, Roman MJ, Seward J, Shanewise JS, Solomon SD, Spencer KT, Sutton MS, Stewart WJ, Chamber Quantification Writing Group, American Society of Echocardiography's Guidelines and Standards Committee; European Association of Echocardiography: Recommendations for chamber quantification: a report from the American Society of Echocardiography's Guidelines and Standards Committee and the Chamber Quantification Writing Group, developed in conjunction with the European Association of Echocardiography, a branch of the European Society of Cardiology. J Am Soc Echocardiogr 2005; 18: 1440-1463. 
20. Patel MR, Dehmer GJ, Hirshfeld JW, Smith PK, Spertus JA, ACCF/SCAI/STS/AATS/AHA/ASNC 2009 Appropriateness Criteria for Coronary Revascularization: A Report of the American College of Cardiology Foundation Appropriateness Criteria Task Force, Society for Cardiovascular Angiography and Interventions, Society of Thoracic Surgeons, American Association for Thoracic Surgery, American Heart Association, and the American Society of Nuclear Cardiology: Endorsed by the American Society of Echocardiography, the Heart Failure Society of America, and the Society of Cardiovascular Computed Tomography. Circulation 2009; 119: 1330-1352.

21. Gersh BJ, Maron BJ, Bonow RO, Dearani JA, Fifer MA, Link MS, Naidu SS, Nishimura RA, Ommen SR, Rakowski H, Seidman CE, Towbin JA, Udelson JE, Yancy CW; American College of Cardiology Foundation/American Heart Association Task Force on Practice Guidelines.. 2011 ACCF/AHA guideline for the diagnosis and treatment of hypertrophic cardiomyopathy: a report of the American College of Cardiology Foundation/American Heart Association Task Force on Practice Guidelines. Developed in collaboration with the American Association for Thoracic Surgery, American Society of Echocardiography, American Society of Nuclear Cardiology, Heart Failure Society of America, Heart Rhythm Society, Society for Cardiovascular Angiography and Interventions, and Society of Thoracic Surgeons. J Am Coll Cardiol 2011; 58: e212e260.

22. Seggewiss H, Rigopoulos A, Welge D, Ziemssen P, Faber L. Long-term follow-up after percutaneous septal ablation in hypertrophic obstructive cardiomyopathy. Clin Res Cardiol 2007; 96: 856-863.

23. Bartúnek J, Sys SU, Heyndrickx GR, Pijls NH, De Bruyne B. Quantitative coronary angiography in predicting functional significance of stenoses in an unselected patient cohort. J Am Coll Cardiol 1995; 26: 328-334.

24. Pijls NH, Bech GJ, De Bruyne B, van Straten A. Clinical assessment of functional stenosis severity: use of coronary pressure measurements for the decision to bypass a lesion. Ann Thorac Surg 1997; 63(6 Suppl): S6-S11.

25. Lim MJ, Kern MJ. Coronary pathophysiology in the cardiac catheterization laboratory. Curr Probl Cardiol 2006; 31: 493-550.

26. Gary DW, Jeffrey FS, Judith T, Andrew NR, Congenital heart disease. In Douglas PZ, Peter L, Robert OB, Eugene B, eds. Braunwald's heart diseas: a textbook of cardiovascular medicine. 17ht ed., Elsevire Saunders, Philadelphia, 2005: 1489-1552. 
27. Alyan O, Ozeke O, Golbasi Z. Coronary artery-left ventricular fistulae associated with apical hypertrophic cardiomyopathy. Eur J Echocardiogr 2006; 7: 326-329.

28. Said SA, van der Werf T. Dutch survey of coronary artery fistulas in adults: congenital solitary fistulas. Int J Cardiol 2006; 106: 323-332.

29. Gowda RM, Vasavada BC, Khan IA. Coronary artery fistulas: clinical and therapeutic considerations. Int J Cardiol 2006; 107: 7-10

30. Chelliah R., Senior R., An update on contrast echocardiography, Minerva Cardioangiol 2009; 57: 483-493.

31. Nagel E, Lima JA, George RT, Kramer CM. Newer methods for noninvasive assessment of myocardial perfusion: cardiac magnetic resonance or cardiac computed tomography? JACC Cardiovasc. Imaging 2009; 2: 656-660.

32. Hachamovitch R., Berman D.S., Kiat H., Cohen I., Cabico J.A., Friedman J. et al., Exercise myocardial perfusion SPECT in patients without known coronary artery disease: incremental prognostic value and use in risk stratification. Circulation 1996; 93: 905-914.

33. Al-Mallah MH, Sitek A, Moore SC, Di Carli M, Dorbala S. Assessment of myocardial perfusion and function with PET and PET/CT. J Nucl Cardiol 2010; 17: 498-513.

34. Blankstein R, Di Carli MF. Integration of coronary anatomy and myocardial perfusion imaging, Nat Rev Cardiol 2010; 7: 226-236.

35. Miller JM, Rochitte CE, Dewey M, Arbab-Zadeh A, Niinuma H, Gottlieb I Paul N, Clouse ME, Shapiro EP, Hoe J, Lardo AC, Bush DE, de Roos A, Cox C, Brinker J, Lima JA. Diagnostic performance of coronary angiography by 64-row CT. N Engl J Med 2008; 359: 2324-2336.

36. Wijns W, De Bruyne B, Vanhoenacker PK. What does the clinical cardiologist need from noninvasive cardiac imaging: is it time to adjust practices to meet evolving demands? Nucl Cardiol 2007; 14: 366-370.

37. Vogelzang M, Vlaar PJ, Svilaas T, Amo D, Nijsten MW, Zijlstra F. Computer-assisted myocardial blush quantification after percutaneous coronary angioplasty for acute myocardial infarction: a substudy from the TAPAS trial. Eur Heart J 2009; 30: 594-599.

38. Leung DY, Leung M. Non-invasive/invasive imaging: significance and assessment of coronary microvascular dysfunction. Heart 2011; 97: 587-595.

39. Havers J, Haude M, Erbel R, Spiller P. X-ray densitometric measurement of myocardial perfusion reserve in symptomatic patients without angiographically detectable coronary stenoses. Herz 2008; 33: 223-232. 
40. Pijls NH, Van Gelder B, Van der Voort P, Peels K, Bracke FA, Bonnier HJ, el Gamal MI. Fractional flow reserve. A useful index to evaluate the influence of an epicardial coronary stenosis on myocardial blood flow. Circulation 1995; 92: 3183-3193.

41. Abaci A, Oguzhan A, Eryol NK, Ergin A. Effect of potential confounding factors on the thrombolysis in myocardial infarction (TIMI) trial frame count and its reproducibility, Circulation1999; 100: 2219-2223.

42. Haeck JD, Gu YL, Vogelzang, M, Bilodeau L, Krucoff MW, Tijssen JG, De Winter RJ, Zijlstra F, Koch KT. Feasibility and applicability of computer-assisted myocardial blush quantifi cation after primary percutaneous coronary intervention for ST-segment elevation myocardial infarction. Catheter Cardiovasc Interv 2010; 75: 701-706.

43. Nagy FT, Sasi V, Ungi T, Zimmermann Z, Ungi I, Kalapos A, Forster T, Nemes A. Correlations between myocardium selective videodensitometric perfusion parameters and corrected TIMI frame count in patients with normal epicardial coronary arteries. Int J Cardiol 2012; 155: 498-501.

44. Nemes A, Kalapos A, Sasi V, Ungi T, Nagy FT, Zimmermann Z, Forster T, Ungi I. Detection of perfusion abnormalities on coronary angiograms in hypertension by myocardium selective densitometric perfusion assessments. Int J Cardiol 2012; 157: 428-429.

45. Nagy FT, Horváth T, Ungi T, Sasi V, Zimmermann Z, Kalapos A, Forster T, Ungi I, Nemes A. Aortic valve stenosis is associated with reduced myocardial perfusion as assessed by videodensitometry in coronary angiograms. Orv Hetil 2012; 153: 12561262.

46. Nemes A, Kalapos A, Sasi V, Ungi T, Ungi I, Forster T, Sepp R. Videodensitometric time-density curve change after alcohol septal ablation of obstructive hypertrophic cardiomyopathy. Neth Heart J 2015; 23: 143-144.

47. Hoffmann R, Haager P, Arning J, Christott P, Radke P, Blindt R, Ortlepp J, Lepper W, Hanrath P. Usefulness of myocardial blush grade early and late after primary coronary angioplasty for acute myocardial infarction in predicting left ventricular function. Am J Cardiol 2003; 92: 1015-1019.

48. Bellandi F, Leoncini M, Maioli M, Toso A, Gallopin M, Piero Dabizzi R. Markers of myocardial reperfusion as predictors of left ventricular function recovery in acute myocardial infarction treated with primary angioplasty. Clin Cardiol 2004; 27: 683-688.

49. Bax M, de Winter RJ, Schotborgh CE, Koch KT, Meuwissen M, Voskuil M, Adams R, Mulder KJ, Tijssen JG, Piek JJ. Short- and long-term recovery of left ventricular 
function predicted at the time of primary percutaneous coronary intervention in anterior myocardial infarction. J Am Coll Cardiol 2004; 43: 534-541.

50. Wu KC, Zerhouni EA, Judd RM, Lugo-Olivieri CH, Barouch LA, Schulman SP, Blumenthal RS, Lima JA. Prognostic significance of microvascular obstruction by magnetic resonance imaging in patients with acute myocardial infarction. Circulation 1998; 97: 765-772.

51. Aarnoudse W, Fearon WF, Manoharan G, Geven M, van de Vosse F, Rutten M, De Bruyne B, Pijls NH. Epicardial stenosis severity does not affect minimal microcirculatory resistance. Circulation 2004; 110: 2137-2142.

52. Henriques JP, Zijlstra F, van't Hof AW, de Boer MJ, Dambrink JH, Gosselink M, Hoorntje JC, Suryapranata H. Angiographic assessment of reperfusion in acute myocardial infarction by myocardial blush grade. Circulation 2003; 107: 2115-2119.

53. Choi KM, Kim RJ, Gubernikoff G, Vargas JD, Parker M, Judd RM. Transmural extent of acute myocardial infarction predicts long-term improvement in contractile function. Circulation 2001; 104: 1101-1107.

54. Yamanaka O, Hobbs RE. Coronary artery anomalies in 126,595 patients undergoing coronary arteriography. Cathet Cardiovasc Diagn 1990; 21: 28-40.

55. Cheon WS, Kim EJ, Kim SH, Choi YJ, Rhim CY. Bilateral coronary artery fistulas communicating with main pulmonary artery and left ventricle: case report. Angiology 2007; 58: 118-121.

56. Alkhulaifi AM, Horner SM, Pugsley WB, Swanton RH. Coronary artery fistulas presenting with bacterial endocarditis. Ann Thorac Surg 1995; 60: 202-204.

57. Lau G. Sudden death arising from a congenital coronary artery fistula. Forensic Sci Int 1995; 73: 125-130.

58. Liu PR, Leong KH, Lee PC, Chen YT. Congenital coronary artery-cardiac chamber fistulae: a study of fourteen cases. Zhonghua Yi Xue Za Zhi (Taipei) 1994; 54: 160165.

59. Kilic H, Akdemir R, Bicer A, Dogan M. Transcatheter closure of congenital coronary arterial fistulas in adults. Coron Art Dis 2008; 19: 43-45.

60. Sasi V, Ungi I, Forster T, Nemes A. Multiple coronary fistulas originating from all major coronary arteries. Acta Cardiol 2010; 65: 357-360.

61. Härle T, Kronberg K, Elsässer A. Coronary artery fistula with myocardial infarction due to steal syndrome. Clin Res Cardiol 2012; 101: 313-315. 
62. Werner GS, Fritzenwanger M, Prochnau D, Schwarz G, Ferrari M, Aarnoudse W, Pijls NH, Figulla HR. Determinants of coronary steal in chronic total coronary occlusions donor artery, collateral, and microvascular resistance. J Am Coll Cardiol 2006; 48: 5158.

63. Armsby LR, Keane JF, Sherwood MC, Forbess JM, Perry SB, Lock JE. Management of coronary artery fistulae. Patient selection and results of transcatheter closure. J Am Coll Cardiol 2002; 39: 1026-1032.

64. Katona A, Ungi I, Forster T, Katona M, Nemes A.A single coronary artery with a right ventricular fistula: unique therapy with covered-stent implantation.Herz 2014; 39: 725726. 


\section{Acknowledgments}

The studies reported in this work were performed in the 2nd Department of Medicine and Cardiology Center, Medical Faculty, Albert Szent-Györgyi Clinical Center, University of Szeged, Hungary.

I am especially indebted to Prof. Dr. Attila Nemes, who was my tutor and scientific adviser. Without his support and encouragement this work could not be done.

I would like to express my acknowledgement to Prof. Dr. Tamás Forster, the head of the 2nd Department of Medicine and Cardiology Center for all of his patience and support to my work.

I would like to express my gratefullness to my boss Dr. Imre Ungi for giving me huge support throuhout my work.

I would like to thank to my co-authors who gave me support and to the staff of the Department of Invasive Cardiology.

Last, but not least I would like to express my deepest gratitude to my parents and my family who were always with me. 
Photocopies of essential publications 